\title{
Automation and Job Polarization: On the Decline of Middling Occupations in Europe
}

\author{
Vahagn Jerbashian*
}

\begin{abstract}
Using data from 10 Western European countries, I provide evidence that the fall in prices of information technologies (IT) is associated with a lower share of employment in middle wage occupations and a higher share of employment in high wage occupations in industries which depend more on IT relative to industries which depend less. Similar results hold within gender and age groups, with notable differences in these groups. For instance, the share of employment in high wage occupations among males has increased less than among females with the fall in IT prices.
\end{abstract}

Keywords: Job Polarization; Information Technologies; Gender; Age

JEL classification: J23; J24; O33

\footnotetext{
*University of Barcelona, BEAT, and CERGE-EI. Correspondence address: Av. Diagonal 696, 08034 Barcelona, Spain. E-mail: vahagn.jerbashian@ub.edu. Phone: +34934034890.

CERGE-EI is a joint workplace of the Center for Economic Research and Graduate Education, Charles University in Prague, and the Economics Institute of Academy of Sciences of the Czech Republic.
} 


\section{Introduction}

For quite some time, the consensus has been that most of the recent technological changes have been skill-biased, complementing high-skill workers and substituting for low-skill workers (see, e.g., Katz and Autor, 1999). However, skill-biased technological change alone cannot explain a prominent and relatively recent phenomenon: the decline in the share of middle wage occupations relative to high and low wage occupations. Goos and Manning (2007) call this phenomenon "job polarization."

One of the main hypotheses put forward for job polarization is that recent technologies, such as computers, substitute for routine tasks. These tasks tend to be readily automatable and are usually performed by middle wage occupations, such as stationary-plant operators. They complement nonroutine cognitive tasks, which are usually performed by high wage occupations, such as managers. In turn, the rise of employment in highly paid occupations increases the demand for nonroutine manual tasks, which are usually performed by low wage occupations, such as personal services (see, e.g., Autor, Levy, and Murnane, 2003, Autor and Dorn, 2013, Mazzolari and Ragusa, 2013).

In this paper, I empirically investigate the effect of the rapid fall in prices of information technologies (IT) on industries' demand for high, middle and low wage occupations using a difference-in-differences framework in the spirit of Rajan and Zingales (1998). More specifically, I ask whether the fall in prices of information technologies has affected the demand for high, middle and low wage occupations more in industries which depend more on IT compared to industries which depend less. I use industry- and country-level data from 10 Western European countries for 1993-2007 to establish the results.

I find that the share of employment in middling occupations has declined and the share of employment in high wage occupations has increased with the fall in IT prices in industries with high dependence on IT relative to industries with low dependence on IT. I find no systematic evidence that the fall in IT prices affects the share of employment in the lowest paid occupations. Similar results hold within gender and age groups. These findings provide support for the hypothesis put forward for explaining job polarization. They are broadly in line with and complement the results of Autor et al. (2003), Acemoglu 
and Autor (2011), Autor and Dorn (2013), and Goos, Manning, and Salomons (2014), among others.

I also find that there are differences among gender and age groups, which is a novelty relative to these papers. The fall in IT prices has increased the share of employment in high wage occupations and reduced the share of employment in medium wage occupations among males less than among females in industries which depend more on IT relative to industries which depend less. It has also increased the share of employment in high wage occupations and reduced the share of employment in medium wage occupations among old workers less than among young and medium-age workers in industries which depend more on IT relative to industries which depend less. These results are robust to a wide range of specification checks and alternative identifying assumptions.

A possible common explanation for these results is that the efficiency (comparative advantage) of performing tasks in medium and high wage occupations varies with gender and age. For example, males tend to be more endowed with hard motor skills (brawn) than females, and these skills are usually important in many of the medium wage manufacturing occupations. In turn, a number of papers argue that females have better communication and social skills, which have a growing importance in the labor market and tend to be more important in leadership in high wage occupations (e.g., Beaudry and Lewis, 2014, Borghans, Weel, and Weinberg, 2014, Deming, 2017). The adoption and use of information technologies would then reduce employment in medium wage occupations and increase employment in high wage occupations among males less than among females. In turn, information technologies will have a lower effect on the share of employment in medium and high wage occupations among old if workers accumulate routine-skills more than other types of skills as they age (see, for arguments supporting this conjecture, Autor and Dorn, 2009). I do not attempt to test these hypotheses in this paper given its scope and the available data. All in all, these results highlight the role of gender and age group in job polarization and suggest a need for a more nuanced view on the labor market effects of recent technological changes.

Job polarization is a pervasive phenomenon in developed economies. Goos and Man- 
ning (2007), Goos, Manning, and Salomons (2009) and Goos et al. (2014) provide comprehensive evidence for it for Western European countries and Autor, Katz, and Kearney (2006, 2008), Acemoglu and Autor (2011) and Autor and Dorn (2013) for the US. Recent technological changes are thought to be one of the primary causes of job polarization, and a growing number of papers offer evidence corroborating this view. Using US data, Autor et al. (2003) show that the use of computers (a type of IT) is associated with reduced employment in middle wage (routine) occupations within industries. Autor and Dorn (2013) show that, in the US, the growth of workplace computer use has been faster in areas which had initially high proportions of routine workers. Goos et al. (2014) show that during the period of 1993-2010 employment has declined in routine task intensive occupations in 16 Western European countries.

The polarization of employment is also mirrored in education-level groups. Acemoglu and Autor (2011) show that in the US the demand for workers with high- and lowlevels of education has increased relative to the demand for workers with medium-level of education. Using data from 11 OECD countries, Michaels, Natraj, and van Reenen (2014) provide evidence that industries with faster growth in information and communication technologies have increased the demand for highly educated workers at the expense of middle-educated, with almost no effect on low-educated workers.

A few recent papers independently explore the differences in the trends of polarization across genders using US data (e.g., Cerina, Moro, and Rendall, 2017, Cortes, Jaimovich, and Siu, 2018). Cerina et al. (2017) document that job polarization is more prevalent among females than among males. The results of the current study suggest that the fall in prices of information technologies can be one of the rationales of their finding. ${ }^{1}$

The main focus of this paper is on how the fall in IT prices has affected the demand for high, medium and low wage occupations. Several recent studies suggest that structural transformation and changes in relative productivities of occupations and industries can also explain the observed changes in the demand for employment in these occupation groups (see, e.g., Aum, Lee, and Shin, 2018, Bárány and Siegel, 2018, Gallipoli and

\footnotetext{
${ }^{1}$ These results also support a view held by, for example, the World Bank and the UN that IT can empower women (see, e.g., United Nations, 2005, Melhem, Morrell, and Tandon, 2009).
} 
Makridis, 2018). ${ }^{2}$ This evidence implies that more general processes than the fall in IT prices can have a role in job polarization. In line with this evidence, I show in the additional results section that changes in the prices of physical capital, a more ubiquitous processes, affect employment in these occupation groups and this is over and above the effects of information technologies.

The findings of this study complement the results of these papers. An innovation of this study is its identification strategy. I use the assignment of occupations into task/wage groups by Goos et al. (2014) to compute employment in occupation groups with different task contents and utilize a difference-in-differences framework à la Rajan and Zingales (1998). In this framework, I employ the variation of IT prices over time and the industry-level variation of dependence on IT, which allows me to explicitly take into account the technological side of the effect of the fall in IT prices on employment. I provide international evidence corroborating the hypothesis for job polarization. By exploring differences among industries and in gender and age groups, I also uncover some more concealed features of the effects of recent technological changes on labor markets in Europe.

The next section describes a simple model to motivate the empirical test. The third section offers the empirical specification, and describes the data and its sources. The fourth section summarizes the results. The last section concludes.

\section{Theoretical Background}

Recent omnipresent advances in information technologies have caused the prices of these technologies to fall. Technological advances in IT and the resulting fall in IT prices would increase demand for nonroutine cognitive (abstract) task intensive occupations and reduce demand for routine task intensive occupations more in industries which depend more on information technologies. I present a simple model to show explicitly how such an inference can hold and to set the stage for the empirical analysis. The model is based

\footnotetext{
${ }^{2}$ Aum et al. (2018) and Gallipoli and Makridis (2018) emphasize the role of IT producing and IT-intensive sectors and IT-intensive occupations in the processes of structural transformation and changes in the demand for occupations.
} 
on the models of Acemoglu and Autor (2011) and Autor and Dorn (2013). In particular, I model the demand for abstract and routine tasks and incorporate technological advances in IT in a similar way to Autor and Dorn (2013). I also incorporate comparative advantage differences in the performance of tasks among broad worker groups as in the model of Acemoglu and Autor (2011).

The producers use abstract and routine task inputs, $T_{A}$ and $T_{R}$, and information technologies, IT, to produce homogeneous goods, $Y$. They have a CES production technology, which is given by

$$
Y=\left(\alpha_{I T} I T^{\frac{\varepsilon-1}{\varepsilon}}+\alpha_{T_{R}} T_{R}^{\frac{\varepsilon-1}{\varepsilon}}\right)^{\frac{\varepsilon}{\varepsilon-1} \alpha} T_{A}^{1-\alpha},
$$

where $\alpha_{I T}>0, \alpha_{T_{R}}>0, \alpha \in(0,1)$, and $\varepsilon>1$. In the production of $Y, \alpha_{I T}$ measures the relative importance of $I T$ and a higher $\alpha_{I T}$ implies higher share of compensation for IT. In this sense, it measures the technological dependence on IT. In turn, $\varepsilon$ is the elasticity of substitution between routine tasks and information technologies, and the elasticity of substitution between abstract tasks and information technologies is equal to 1 , by construction. Since $\varepsilon>1$, information technologies are more complementary to abstract tasks than to routine tasks.

The usual profit maximization implies the following conditions

$$
\begin{aligned}
& I T=\alpha \frac{\alpha_{I T} I T^{\frac{\varepsilon-1}{\varepsilon}}}{\alpha_{I T} I T^{\frac{\varepsilon-1}{\varepsilon}}+\alpha_{T_{R}} T_{R}^{\frac{\varepsilon-1}{\varepsilon}}} \frac{1}{p_{I T}} Y, \\
& T_{R}=\alpha \frac{\alpha_{T_{R}} T_{R}^{\frac{\varepsilon-1}{\varepsilon}}}{\alpha_{I T} I T^{\frac{\varepsilon-1}{\varepsilon}}+\alpha_{T_{R}} T_{R}^{\frac{\varepsilon-1}{\varepsilon}} \frac{1}{p_{T_{R}}} Y,} \\
& T_{A}=(1-\alpha) \frac{1}{p_{T_{A}}} Y,
\end{aligned}
$$

where $p_{I T}, p_{T_{R}}$, and $p_{T_{A}}$ are the prices of information technologies and task inputs, and the price of $Y$ is normalized to 1 .

I assume that information technologies input can be represented as $I T=\lambda I \bar{T}$, where $\lambda$ represents the quality/productivity of information technologies and it grows over time because of technological progress. I also assume that $p_{I T}, p_{T_{A}}$, and $p_{T_{R}}$ are determined 
at the country level and that the growth in $\lambda$ does not affect $p_{T_{A}}$ and $p_{T_{R}}{ }^{3}$ This implies that the derivative of the demand for $T_{A}$ relative to $T_{R}$ with respect to $\lambda$ and the change of that derivative with $\alpha_{I T}$ are given by

$$
\frac{\partial T_{A} / T_{R}}{\partial \lambda}=\frac{\varepsilon-1}{\varepsilon} \frac{1-\alpha}{\alpha} \frac{p_{T_{R}}}{p_{T_{A}}} \frac{\alpha_{I T} I T^{\frac{\varepsilon-1}{\varepsilon}}}{\alpha_{T_{R}} T_{R}^{\frac{\varepsilon-1}{\varepsilon}}} \frac{1}{\lambda},
$$

and

$$
\frac{\partial}{\partial \alpha_{I T}} \frac{\partial T_{A} / T_{R}}{\partial \lambda}=\frac{1}{\alpha_{I T}} \frac{\partial T_{A} / T_{R}}{\partial \lambda}
$$

It is straightforward to show that the growth in $\lambda$ reduces $p_{I T}$. Moreover, it increases the demand for $T_{A}$ more than the demand for $T_{R}$ when $\varepsilon>1$, according to equation (5). According to equation (6), in a country, the demand for $T_{A}$ relative to $T_{R}$ would increase more in industries with higher $\alpha_{I T}$ than in industries with lower $\alpha_{I T}$ with the growth in $\lambda$ in such a case. This means that $T_{A}$ increases and $T_{R}$ declines with the growth of $\lambda$ and the corresponding decline in $p_{I T}$ if employment in $Y$ is fixed and these changes are larger in industries with a larger $\alpha_{I T}{ }^{4}$

It can be shown that such differential changes can also hold within gender and age groups incorporating these demand functions into a simple Ricardian model of comparative advantage. To do so, I assume that workers are endowed with labor hours, which need to be converted into abstract and routine tasks in order to earn market income. I assume that the conversion function of task $k=T_{A}, T_{R}$ is given by $\alpha_{L, k}\left(u_{k} L\right)^{\gamma}$, where $\alpha_{L, k}>0, u_{k}$ is the share of labor hours $L$ converted to task $k$, and $\gamma \in(0,1) .{ }^{5}$ I normalize the value of $\alpha_{L, T_{A}}$ to 1 .

This setup implies that the supply of abstract tasks relative to the supply of routine

\footnotetext{
3 The latter assumption might not seem very strong since this paper focuses on the differential effects of growth in $\lambda$ and fall in $p_{I T}$ on the demand for tasks among industries with different $\alpha_{I T}$. I endogenize the supply of tasks and $p_{T_{A}}$ and $p_{T_{R}}$ at the end of this section and show that it is innocuous.

${ }^{4}$ I extend this analysis and consider a two-sector model, where sectors have different levels of $\alpha_{I T}$ and the allocation of IT between sectors is endogenous, in the Online Technical Appendix. I show that the inference in equation (6) also holds in such an extended model. Another extension of the analysis considers a nested CES production function in equation (1). It can be shown that, in such an extension, a sufficient condition for having positive left-hand side in equations (5) and (6) is that the elasticity of substitution between $I T$ and $T_{R}$, $\varepsilon$, is larger than the elasticity of substitution between $I T$ and $T_{A}$ and it is greater than 1.

${ }^{5}$ Parameters $\alpha_{L, T_{A}}$ and $\alpha_{L, T_{R}}$ can admit a range of interpretations since they can represent both supply and demand side factors.
} 
tasks is given by

$$
\frac{p_{T_{A}}}{p_{T_{R}}}=\alpha_{L, T_{R}}\left(\frac{u_{T_{R}}}{u_{T_{A}}}\right)^{\gamma-1}
$$

and the share of employment in abstract tasks is given by

$$
\frac{u_{T_{A}}}{1-u_{T_{A}}}=\frac{1-\alpha}{\alpha}\left(\frac{\alpha_{I T} I T^{\frac{\varepsilon-1}{\varepsilon}}}{\alpha_{T_{R}}\left\{\alpha_{L, T_{R}}\left[\left(1-u_{T_{A}}\right) L\right]^{\gamma}\right\}^{\frac{\varepsilon-1}{\varepsilon}}}+1\right) .
$$

It is straightforward to show that in this model economy the growth in $\lambda$ increases the share of employment in abstract tasks $u_{T_{A}}$ and it has a stronger effect in industries which have a higher $\alpha_{I T}$. However, these differential effects on employment shares are weaker in groups which have a comparative advantage in converting labor hours into routine tasks (i.e., a higher $\left.\alpha_{L, T_{R}}\right)$ :

$$
\frac{\partial}{\partial \alpha_{L, T_{R}}} \frac{\partial}{\partial \alpha_{I T}} \frac{\partial u_{T_{A}}}{\partial \lambda}<0
$$

The differential changes in $T_{A}$ and $T_{R}$ in industries which depend more on $I T$ than in industries which depend less on IT should be observed in the data as differential changes in the employment in high and medium wage occupations which perform these tasks. I look exactly for such disparities and differential changes in the empirical specification and utilize IT price variation as a proxy for technological advances/shocks in IT.

\section{Empirical Methodology and Data}

I start with estimating the differential effect of the rapid fall in IT prices on employment shares in high, middle and low wage occupations in industries which depend more on IT compared to industries which depend less. Let Employment Share ${ }_{c, i, t}$ be the share of employment in one of the occupation groups, country $c$, industry $i$, and year $t$ and IT Price be the measure for the price of information technologies $\left(p_{I T}\right)$. Assuming that I have a measure of industries' technological dependence on IT, I estimate the following 
specification for each occupation group:

$$
\begin{aligned}
\text { Employment Share }_{c, i, t}= & \beta\left[\text { Industry i's Dependence on } \mathrm{IT}_{i} \times(1 / \mathrm{IT} \text { Price })_{c, t}\right] \\
& +\sum_{c} \sum_{i} \zeta_{c, i}+\sum_{c} \sum_{t} \xi_{c, t}+\eta_{c, i, t}
\end{aligned}
$$

where $\zeta$ and $\xi$ are country-industry and country-year fixed effects respectively, and $\eta$ is an error term. In accordance with equation (6), this specification identifies the differential effect of the fall in IT prices on employment shares in occupation groups across industries with different levels of dependence on IT. The parameter of interest is $\beta$. It is identified from the temporal variation of IT prices, the variation of technological dependence on IT across industries, and within country, time, and industry variation of the interaction term.

Rajan and Zingales (1998) have pioneered this type of difference-in-differences identification strategy and have used it to show how financial development affects industry performance. They focus on country and industry variation and regress industry growth measures on the interaction between a proxy of financial dependence of industries and country-level financial development indicators and country and industry fixed effects. In contrast to Rajan and Zingales (1998), I also utilize temporal variation that allows a focus on significant and omnipresent advances in information technologies. ${ }^{6}$

An advantage of this test is that it alleviates endogeneity concerns because of omitted country- and industry-level variables. For example, country-industry and country-year fixed effects alleviate the potentially confounding effects of regulatory and discriminatory practices which affect the demand and supply of the tasks. These fixed effects also alleviate the potentially confounding effects of trends in relative wage rates. Admittedly, however, this test might not fully reveal the effects of the fall in the price of information technologies on employment shares if there are economy-wide changes that are not different across industries. In such a case, this test can be also viewed as a test of whether industry-level differences exist. Results, which show that such differences exist,

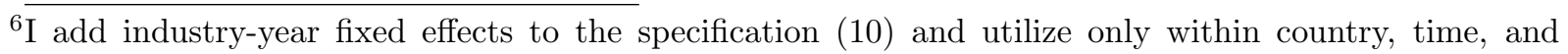
industry variation in robustness tests in the Online Appendix - Further Robustness Checks and Results 
themselves can be considered to be a contribution to the literature on job polarization.

The data for employment in high, medium and low wage occupations in industries are from the harmonized, individual-level EU Labour Force Survey (ELFS). Occupations have ISCO-88 coding and are at 2- and 3-digit aggregation levels in this database, and industries are 1-digit NACE Rev. 1. I use sample weights, and the assignment of occupations into high, medium and low wage groups by Goos et al. (2014), to compute the number of (usual) weekly hours worked in these occupation groups in each sample industry, country, and year. I derive employment shares from the number of hours worked.

Goos et al. (2014) also use ELFS data and exclude from the sample some of the occupations and industries because of sample imperfections and potentially large state involvement. These occupations and industries are also excluded from the analysis in this paper. Moreover, similarly to Goos et al. (2014), I use 2-digit aggregation level for occupations throughout the analysis.

Given data availability, the analysis of this paper focuses on 10 Western European countries and the period between 1993 and 2007. The list of sample countries and the sample period for each country are offered in Table 1 . Table 2 offers the averages of employment shares in high, medium and low wage occupations in sample industries in Panel $A{ }^{7}$ Overall, services industries tend to have higher shares of employment in high and low wage occupations and a lower share of employment in middle wage occupations as compared to manufacturing industries.

I also retrieve information from the ELFS database on gender and age. The data for age are in five-year bands, and the minimum age is 15 . I restrict the maximum age to 65 and create three age groups: young (younger than 30), middle-age (between 30 and 45), and old (older than 45). I compute the number of hours worked in each of these categories for all occupation group-industry cells in sample countries and years. Table 3 offers basic statistics for the employment shares in high, medium and low wage occupations within

\footnotetext{
${ }^{7}$ Table 6 in the Data Appendix offers the assignment of occupations into high, medium and low wage groups. Table A in the Online Appendix - Tables and Figures offers the shares of employment in sample occupations and industries. Figure A in the Online Appendix - Tables and Figures illustrates the trends of employment shares in high, medium and low wage occupations.
} 
each of these categories. The data reveal commonly observed patterns. On average, men work more in high wage occupations and less in low wage occupations than women. The share of employment in high wage occupations is higher and the share of employment in low wage occupations is lower among medium-age and old workers than among young workers.

The data for information technologies are from the EU KLEMS database (O'Mahony and Timmer, 2009). I use the share of IT capital compensation in industrial value added to construct a proxy for industries' dependence on information technologies. This proxy needs to identify the technological differences across industries, i.e., $\alpha_{I T}$. In the theoretical model, it is given by $p_{I T} I T / Y$ and it increases with $\alpha_{I T}$ according to equation (2). ${ }^{8}$ However, it can also vary with factor inputs, which can be problematic if there are differences in the trends of use of factor inputs across countries and industry-country specific taxes and subsidies to factor inputs. This can bias the estimate of $\beta$ in ambiguous directions. As in the rest of the literature following Rajan and Zingales (1998), I use data from US industries to alleviate the effect of such a confounding variation (see, e.g., Barone and Cingano, 2011, Jerbashian and Kochanova, 2017).

The use of US data can be helpful since US is arguably the closest to a laissez faire economy. In US data, the industry-level variation of the share of IT capital compensation accounts for more than 90 percent of the total variation albeit there are significant positive trends in adoption of IT and negative trends in employment in routine tasks in all industries. The ranking of industries according to the share of IT capital compensation is very persistent. These observations suggest that the share of IT capital compensation in US industries is likely to identify the technological differences across industries but not the variation in factor input levels. The measure for industries' dependence on information technologies (IT Dependence) is defined as the share of IT capital compensation in industrial value added in US industries, averaged over the period 1993-2007. This measure firmly correlates with similar measures used in the literature (see, e.g., Chen, Niebel,

\footnotetext{
${ }^{8}$ I present a two-sector version of this model in the Online Technical Appendix and show that the variation of $\alpha_{I T}$ across industries is a primary and key source of variation in $p_{I T} I T / Y$ also in such an extended model.
} 
and Saam, 2016, Jerbashian and Kochanova, 2016, 2017). According to Panel A of Table 1, it also firmly correlates with the share of IT capital compensation in the industries of sample Western European countries, which I average over sample countries and period. I perform a range of robustness checks for it in the Online Appendix - Further Robustness Checks and Results.

I also need a measure for the price of information technologies, $p_{I T}$. To construct it, I obtain the price of investments in information technologies in industries of sample countries from the EU KLEMS database. These technologies include computers and machines which use and depend on computers. Following the model, I normalize the price of investments in information technologies with the price of value added in each industry. The price of investments in information technologies, as well as its normalized counterpart, display a large variation over time, relatively little country-level variation, and almost no industry-level variation. The over time variation can be largely attributed to the significant innovations in IT that occurred over the sample years and mostly in the US. The country-level variation is likely to be stemming from regulations that affect the access to and adoption of IT. In turn, the near absence of industry-level variation suggests that the law of one price holds in sample countries. I average the price of investments in IT relative to the price of value added across industries, in sample countries and years, and use that average as the measure of the price of information technologies, $p_{I T}$.

In the estimations of the baseline specification (10), I use the inverse of this measure. According to the theoretical model, $\beta$ is then expected to be positive for high wage occupations and negative for medium wage occupations as $p_{I T}$ declines and its inverse increases. This parsimonious theoretical model has no predictions for low wage occupations. Nevertheless, $\beta$ can be expected to be nil for these occupations since information technologies are not likely to directly affect employment in these occupations (Autor et al., 2003, Autor and Dorn, 2013). ${ }^{9}$

Table 1 offers basic statistics for the price of information technologies in Panel $B$.

\footnotetext{
${ }^{9} \mathrm{I}$ show that the results are robust to excluding low wage occupations and computing industry-level employment as the sum of employment in high and medium wage occupations in the Online Appendix - Further Robustness Checks and Results.
} 
The price of information technologies has fallen everywhere according to the last column of this panel. I average the price of information technologies across sample countries and illustrate its trend over time in Figure 1. Panel $B$ of Table 2 reports the values of the dependence measure in sample industries. Table 6 in the Data Appendix offers the detailed descriptions of all measures used in this paper.

It is worth clarifying the interpretation of the coefficient of interest, $\beta$. Roughly speaking, the difference-in-differences estimator in the specification (10) splits the sample into four groups according to the magnitude of the fall in prices of information technologies and the dependence on these technologies. For each year, these four groups are composed of the industry-country pairs with high fall in prices and high dependence (HF\&HD), industry-country pairs with high fall in prices and low dependence (HF\&LD), pairs with low fall in prices and high dependence (LF\&HD), and pairs with low fall in prices and low dependence (LF\&LD). The coefficient $\beta$, in this respect, represents the difference in the trends of employment in occupation groups between HF\&HD industry-country pairs relative to HF\&LD industry-country pairs and LF\&HD pairs relative to LF\&LD pairs. It is positive (negative) for an occupation group if employment in that group grows at a higher (lower) rate in HF\&HD industry-country pairs relative to HF\&LD industrycountry pairs than in $L F \& H D$ pairs relative to LF\&LD pairs.

I take the residuals from a regression of the share of employment in an occupation group on country-industry and country-year dummies to illustrate the existence of such differential trends. Figure 2 summarizes the results for the shares of employment in occupation groups, which are relative to their means given that the residuals are demeaned. IT prices have declined over time everywhere, and Panels $A$ and $B$ show that employment has increased (declined) in high (medium) wage occupations with the fall in IT prices in industries with high IT dependence compared to industries with low IT dependence. Moreover, according to Panels $A$ and $B$, these trends in employment shares are stronger in countries where IT prices have declined at a higher rate than in countries where IT prices have declined at a lower rate. In turn, Panel $C$ of Figure 2 shows that there are almost no apparent differential trends in low wage occupations. Moreover, there seem 
to be no trends at all for low wage occupations, which suggests that, on average, employment in low wage occupations may not be affected by the fall in IT prices, at least directly. ${ }^{10}$

\section{Results}

Panel $A$ of Table 4 presents the results from the estimation of the specification (10) for the shares of employment in high, medium and low wage occupations. The estimates of the coefficient $\beta$ are significant and positive for the share of high wage occupations and negative for the share of medium wage occupations. These estimates imply that the fall in the price of information technologies is associated with higher demand for high wage occupations and lower demand for medium wage occupations in industries which depend more on these technologies as compared to industries which depend less. Conversely, the estimate of the coefficient $\beta$ is not significant for the share of employment in low wage occupations. This suggests that, on average, information technologies are not likely to have direct effects on the share of employment in low wage occupations.

One way to compute the magnitude of these results is as follows. I take the industries that rank in the 90th and 10th percentiles of the distribution of IT Dependence and compute the difference between dependence levels in these industries. Further, I take the countries and years where IT Price is in the 10th and 90th percentiles of the distribution of IT Price and compute the difference between the levels of the inverse of IT Price for them. Finally, I compute

$$
\hat{\beta} \times \Delta \mathrm{IT} \text { Dependence } \times \Delta 1 / \mathrm{IT} \text { Price, }
$$

where $\Delta$ stands for the difference operator. Focusing on statistically significant estimates of $\beta$, the computed effect for the share of high wage occupations is 0.034 and -0.033 for medium wage occupations. These numbers correspond to the effect of moving from the

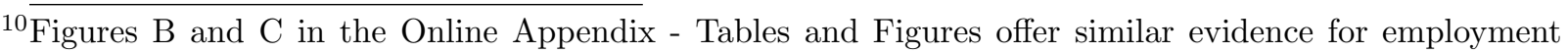
shares in high, medium and low wage occupations in gender and age groups.
} 
pair of country-year with IT Price in the 90th percentile to the pair with IT Price in the 10th percentile in the industry with IT Dependence in the 90th percentile relative to the industry with IT Dependence in the 10th percentile. They suggest that the fall in IT prices has economically large and significant effect on employment shares in high and medium wage occupations, at least relative to the means of these shares, which are 0.389 and 0.387 .

I also estimate the specification (10) for the shares of employment in high, medium and low wage occupations within each gender and age group. The results are reported in Panels $B-F$ of Table 4 . They are broadly consistent with the results for the shares of employment in occupation groups in Panel $A$, with some notable differences among gender and age groups. The fall in IT prices has increased the share of employment in high wage occupations and reduced the share of employment in medium wage occupations among women by about 50 percent more than among men in industries which depend more on IT relative to industries which depend less. It has also increased the share of employment in high wage occupations and reduced the share of employment in medium wage occupations among old workers by about 50 percent less than among young and among medium-age workers. These differences are economically large. They are also statistically significant for genders and for age groups in medium wage occupations at least at the $10 \%$ level according to the standard t-test. The differences are at the borderline of statistical significance for age groups in high wage occupations.

A possible and common interpretation of these results is that the comparative advantage of performing tasks in medium wage and high wage occupation groups varies with gender and age. For example, males tend to be better endowed with hard motor skills (brawn) than females and these skills are commonly more important in many of the medium wage occupations. Meanwhile, women are argued to have an advantage in communication and social skills, which seem to be more important in high wage occupations. All else equal, the adoption and use of information technologies would then reduce employment in medium wage occupations and increase employment in high wage occupations among males less than among females. In turn, information technologies will 
have a lower effect on the share of employment in high and medium wage occupations among old if workers accumulate routine-skills more than other types of skills as they age (i.e., if $\alpha_{L, T_{R}}$ increases with age). ${ }^{11}$

\subsection{Further Results and Robustness Checks}

The demand for IT is a potential source of reverse causality if industries' employment of different tasks affect it. Country-industry and country-year fixed effects in the specification (10) are likely to alleviate such reverse causality concerns given that the main source of variation in IT prices will be technological. Nevertheless, I attempt to further circumvent the reverse causality concerns in two ways. Industries with the heaviest use of information technologies are plausible candidates that affect prices of information technologies. In Panel $A$ of Table 5, I exclude industries which have expenditures on IT higher than the 75 percentile of the distribution of IT expenditures across industries in each country and year. The results in this panel are close to those in Panel $A$ of Table 4.

I also attempt to circumvent the reverse causality problem using the prices of communication technologies (CT Price), such as telephones and other communication infrastructure, as an instrumental variable. The prices of communication technologies have fallen in recent decades similarly to IT prices. This fall is mainly driven by the same technological change as for information technologies. Communication technologies, however, are not likely to be directly related to employment in abstract and routine task requiring occupations because communication technologies are not evident complements or substitutes for these tasks. The data for the prices of communication technologies are from the EU KLEMS database. Panel $B$ of Table 5 presents the results when I instrument IT Price using the prices of communication technologies. These results are very close to those in Panel $A$ of Table 4 .

Omitted variables can be another source of endogeneity. It could be that the effects that the estimates in Panel $A$ of Table 4 identify are not because of the fall in IT prices, but rather because of changes in the prices of new physical capital goods (see, e.g., Krusell,

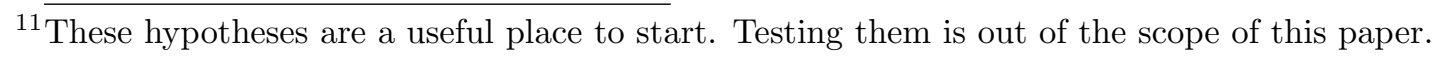


Ohanian, Ríos-Rull, and Violante, 2000).. The movements in the prices of new physical capital goods could be the result of ongoing investment-specific technological change and could cause changes in the demand for physical capital and employment.

To test this hypothesis, I construct an industry-level measure for dependence on physical capital (net of information technology capital) and a country-year-level measure for the price of physical capital. The data for these measures are from the EU KLEMS database, and these measures are constructed in much the same way as the measures of dependence on IT (see Table 6 in the Data Appendix for details). I add to the specification (10) an interaction term between the measure of dependence of industries on physical capital and the inverse of the price of physical capital. Panel $C$ of Table 5 reports the results. The coefficient on the interaction term between IT Dependence and 1/IT Price is very close to the coefficient reported in Panel $A$ of Table 4 . The coefficient on the interaction term between dependence on physical capital and the price of physical capital is significant for the shares of employment in high and medium wage occupations and has the same sign as the coefficient on the main interaction term. These results suggest that more ubiquitous processes, such as changes in the prices of physical capital, affect the share of employment in high and medium wage occupations and this is over and above the effects of information technologies. ${ }^{12}$

According to the theoretical model, the parameter which measures the relative importance of routine tasks in value added, $\alpha_{T_{R}}$, should be important for the analysis similarly to $\alpha_{I T}$. It can be easily shown from equation (5) that the fall in IT prices increases (reduces) the demand for abstract (routine) tasks more in industries with a low $\alpha_{T_{R}}$ than in industries with a high $\alpha_{T_{R}}$. A supplementary test of whether the fall in IT prices has affected employment in high, medium and low wage occupations utilizes this variation. The proxy for $\alpha_{T_{R}}$ can be constructed similarly to the proxy for $\alpha_{I T}$. Ideally, I need data for wages in routine-intensive occupations in order to construct such a proxy. However, there are no data for wages in the ELFS database.

\footnotetext{
${ }^{12}$ The changes in the prices of physical capital can lead to structural changes in the economy. In this respect, these results provide supporting evidence to several recent studies, which link job polarization and structural changes in the economy (e.g., Bárány and Siegel, 2018).
} 
I use wage compensation of medium education-level (skill) employees obtained from the EU KLEMS database as a proxy for the wages in routine-intensive occupations. According to Michaels et al. (2014), this can be a valid proxy because routine-intensive occupations are the middle wage occupations and medium skill/education-level employment tends to be over-represented in these occupations at least in the US. ${ }^{13}$ I measure $\alpha_{T_{R}}$ using the share of compensation of medium education-level employees out of value added in US industries, averaged over the period 1993-2007. I add the interaction of this share with the inverse of IT Price to the specification (10). Panel $D$ of Table 5 reports the results from this exercise. The results for the main interaction term are close to the main results in each regression. In turn, as expected, the estimated coefficient on this additional interaction term has a sign opposite to the sign of the main interaction term.

In the specification (10), country-year fixed effects will not fully capture the trends in relative wage rates if these vary among industries. Such a variation can be expected to be weak according to Kambourov and Manovskii (2009). However, it can confound the identification of $\beta$ if the interaction term is correlated with it. In order to alleviate these concerns, I include in the specification (10) industry group-year dummies and present the results in Panel $E$ of Table 5. I also add to the specification (10) the shares of wage compensation of medium- and low-skill employees out of total wage compensation. The data for these variables are from the EU KLEMS database. Panel $F$ of Table 5 reports the results. In both cases, the results are very similar to the main results suggesting that this is not likely to be a major concern.

The Online Appendix - Further Robustness Checks and Results provides a range of additional robustness check exercises and results. I also perform all of these robustness checks for the shares of employment in high, medium and low wage occupations among gender and age groups.

\footnotetext{
${ }^{13}$ The Online Appendix - Education Levels in Occupation Groups offers an analysis of the relation between employment in middle wage occupations and medium education-level employment for European countries.
} 


\section{Conclusions}

The price of information technologies has fallen in the past few decades because of rapid technological advances. In this study, I use evidence from 10 Western European countries to identify the effect of the fall in IT prices on employment shares in high, medium and low wage occupations in industries with high dependence on IT relative to industries with low dependence on IT. Taken together, my results offer robust evidence that the share of employment in high wage occupations has increased and the share of employment in medium wage occupations has declined with the fall in IT prices in industries which depend more on IT compared to industries which depend less. In turn, I find no systematic evidence that the fall in IT prices affects the share of employment in the lowest paid occupations and that similar results hold within gender and age groups. These results corroborate the polarization hypothesis.

I find certain important differences across gender and age groups, however. The fall in IT prices has increased the share of employment in high wage occupations and reduced the share of employment in medium wage occupations among males by about 50 percent less than among females in the industries which depend more on IT. In these industries, it has also increased the share of employment in high wage occupations and reduced the share of employment in medium wage occupations among old workers by about 50 percent less than among young and medium-age workers. A possible common explanation for such results is that the comparative advantage of performing tasks specific to medium and high wage occupations varies with gender and age. All in all, these results suggest a need for a more nuanced view on the labor market effects of recent technological changes. 


\section{$6 \quad$ Tables and Figures}

Table 1: Sample Countries, IT Price and Correlations of IT Dependence

\begin{tabular}{|c|c|c|c|c|c|c|c|}
\hline \multirow[b]{2}{*}{ Country } & \multirow[b]{2}{*}{ Sample Period } & \multirow{2}{*}{$\begin{array}{l}\text { A. Correlations } \\
\text { IT Dependence }\end{array}$} & \multicolumn{5}{|c|}{ B. Basic Statistics for IT Price } \\
\hline & & & Mean & $\mathrm{SD}$ & Min & $\operatorname{Max}$ & $\Delta$ IT Price \\
\hline Austria & $1995-2007$ & 0.616 & 0.350 & 0.276 & 0.102 & 1.000 & -0.087 \\
\hline Denmark & $1993-2007$ & 0.595 & 0.453 & 0.444 & 0.083 & 1.435 & -0.097 \\
\hline Finland & $1997-2007$ & 0.920 & 0.218 & 0.149 & 0.077 & 0.562 & -0.061 \\
\hline Germany & $1993-2007$ & 0.787 & 0.538 & 0.411 & 0.094 & 1.376 & -0.092 \\
\hline Italy & $1993-2007$ & 0.935 & 0.451 & 0.438 & 0.083 & 1.404 & -0.094 \\
\hline Netherlands & $1993-2007$ & 0.974 & 0.464 & 0.438 & 0.102 & 1.430 & -0.095 \\
\hline Portugal & 1993-2007 & 0.608 & 0.358 & 0.286 & 0.120 & 1.000 & -0.088 \\
\hline Spain & 1993-2007 & 0.914 & 0.496 & 0.385 & 0.127 & 1.280 & -0.082 \\
\hline Sweden & 1997-2007 & 0.909 & 0.545 & 0.230 & 0.228 & 0.849 & -0.059 \\
\hline UK & $1993-2007$ & 0.916 & 0.490 & 0.408 & 0.105 & 1.249 & -0.082 \\
\hline
\end{tabular}

Note: Columns 1-2 of this table list sample countries and period. Panel $A$ offers the pairwise correlations of the measure of dependence on information technologies (IT Dependence) and the shares of IT capital compensation in the industries of the sample of European countries. All correlations are significant at least at the $10 \%$ level. Panel $B$ offers basic statistics for the price of information technologies (IT Price). Column 5 of Panel $B$ offers the average change in IT Price over the sample period in each country ( $\Delta$ IT Price). See Table 6 in the Data Appendix for complete descriptions and sources of variables. 


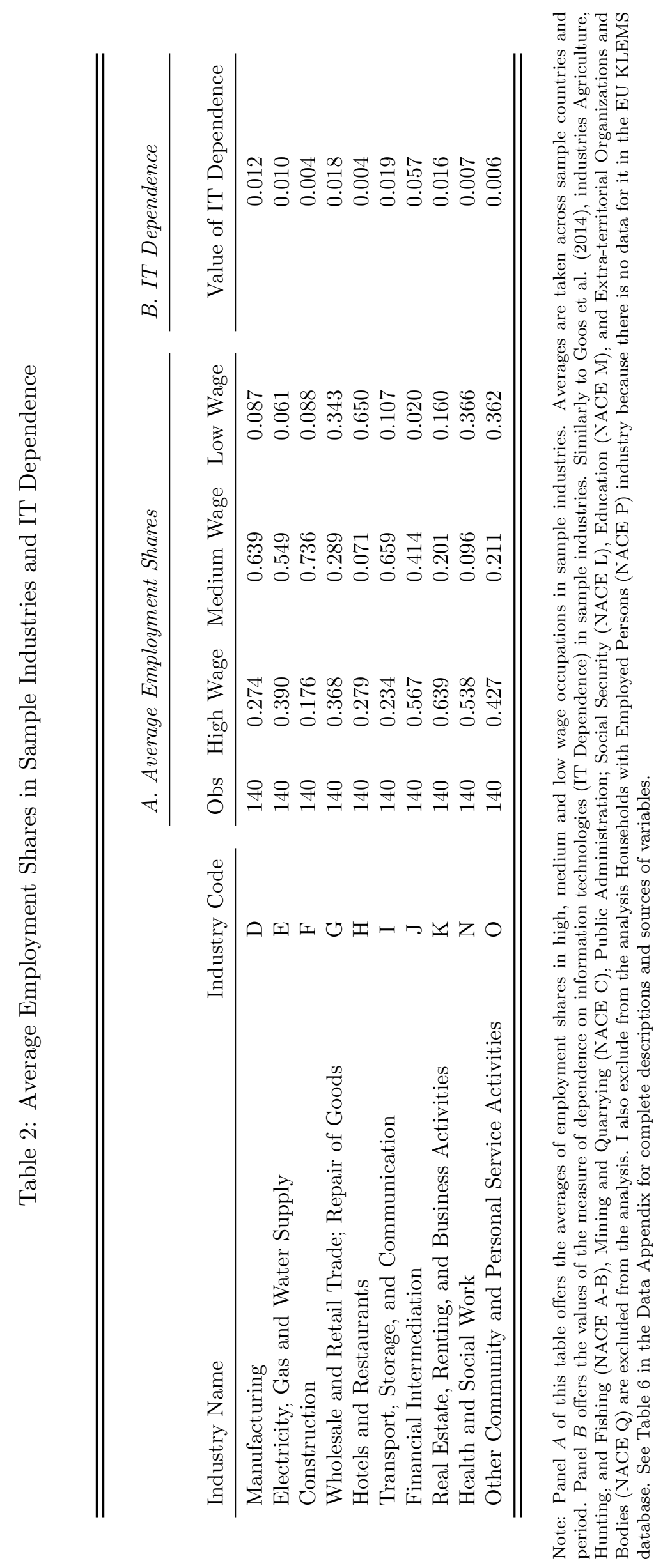




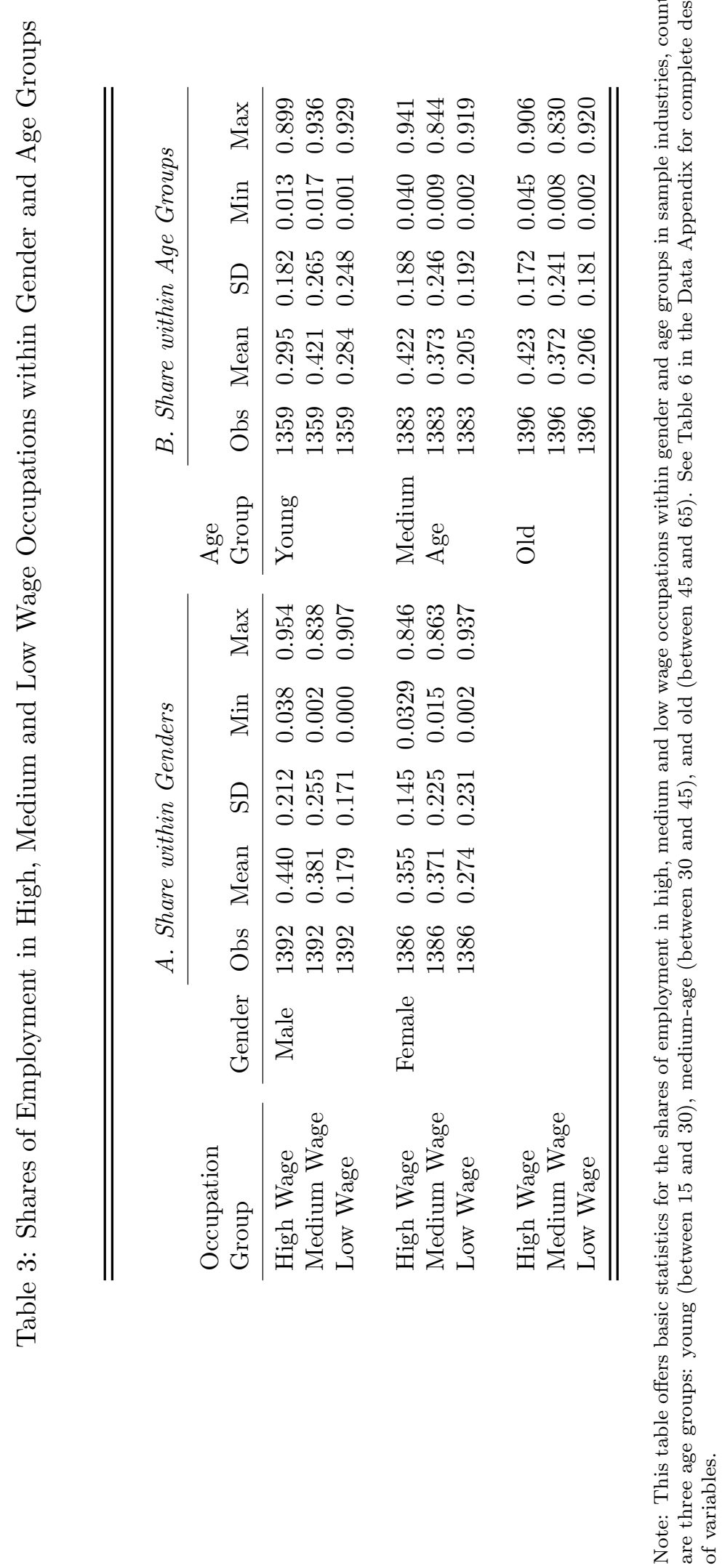




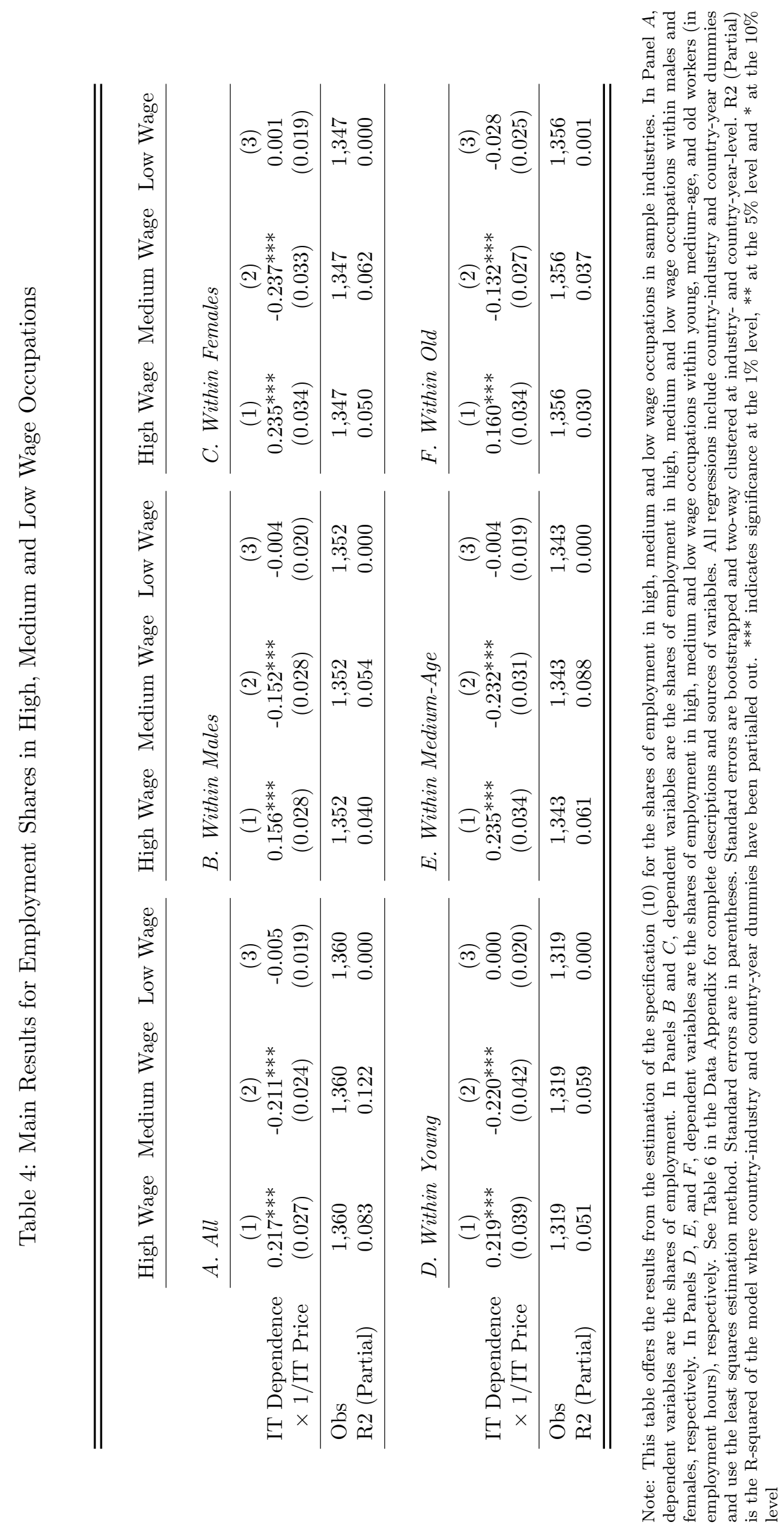




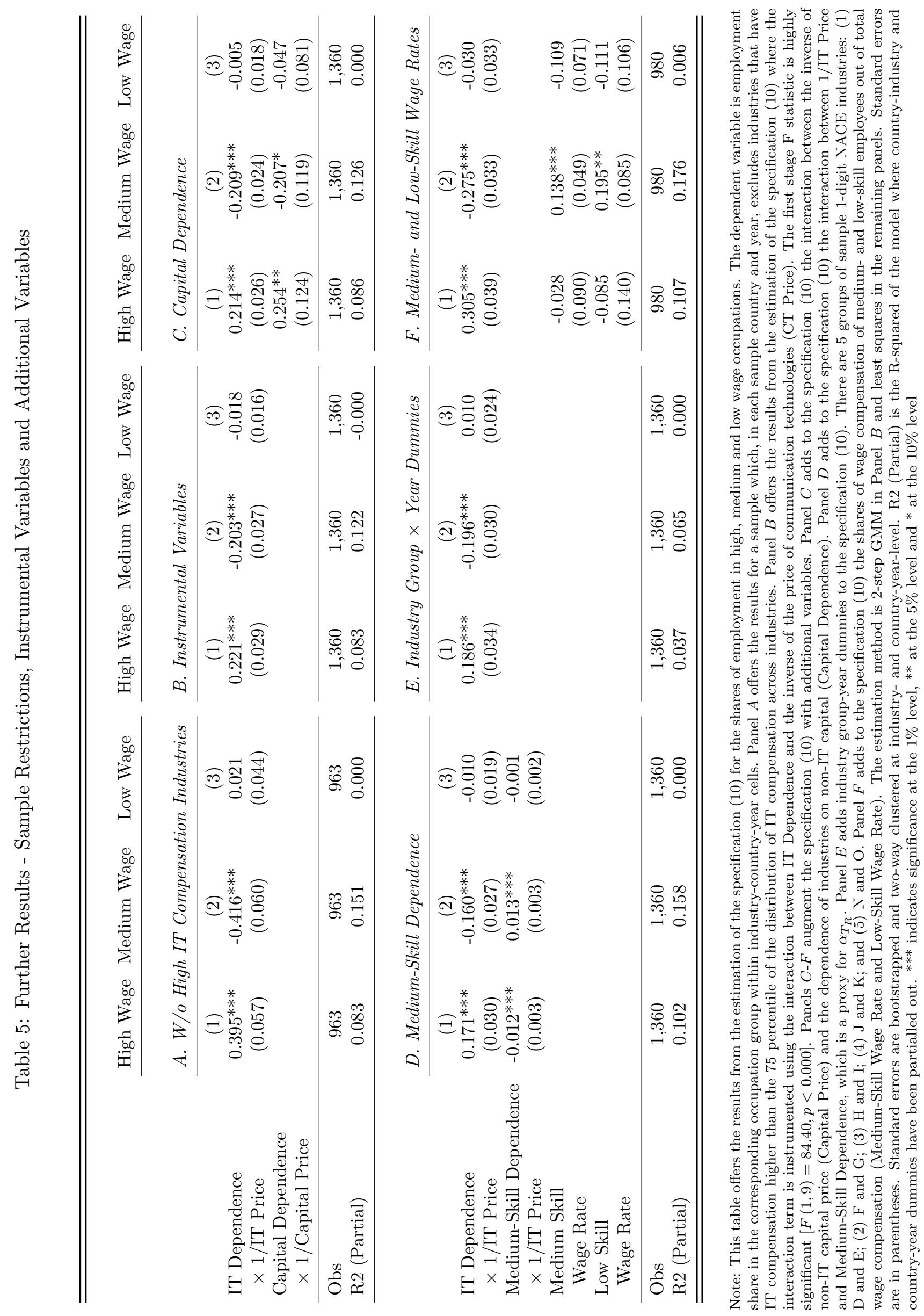


Figure 1: The Price of Information Technologies (IT Price)

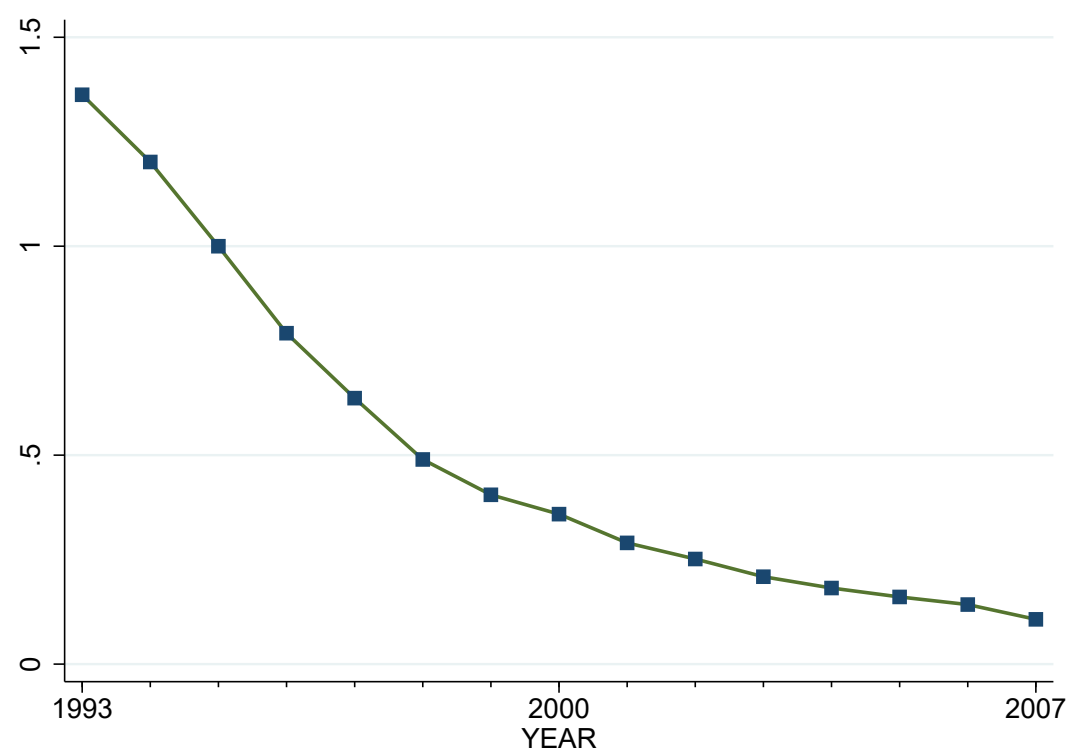

Note: This figure illustrates the evolution of the price of information technologies relative to the price of value added $p_{I T}$ (IT Price). This relative price is averaged across countries. See Table 6 in the Data Appendix for complete descriptions and sources of variables. 
Figure 2: Employment Shares in High, Medium and Low Wage Occupations in High and Low IT Dependence Industries
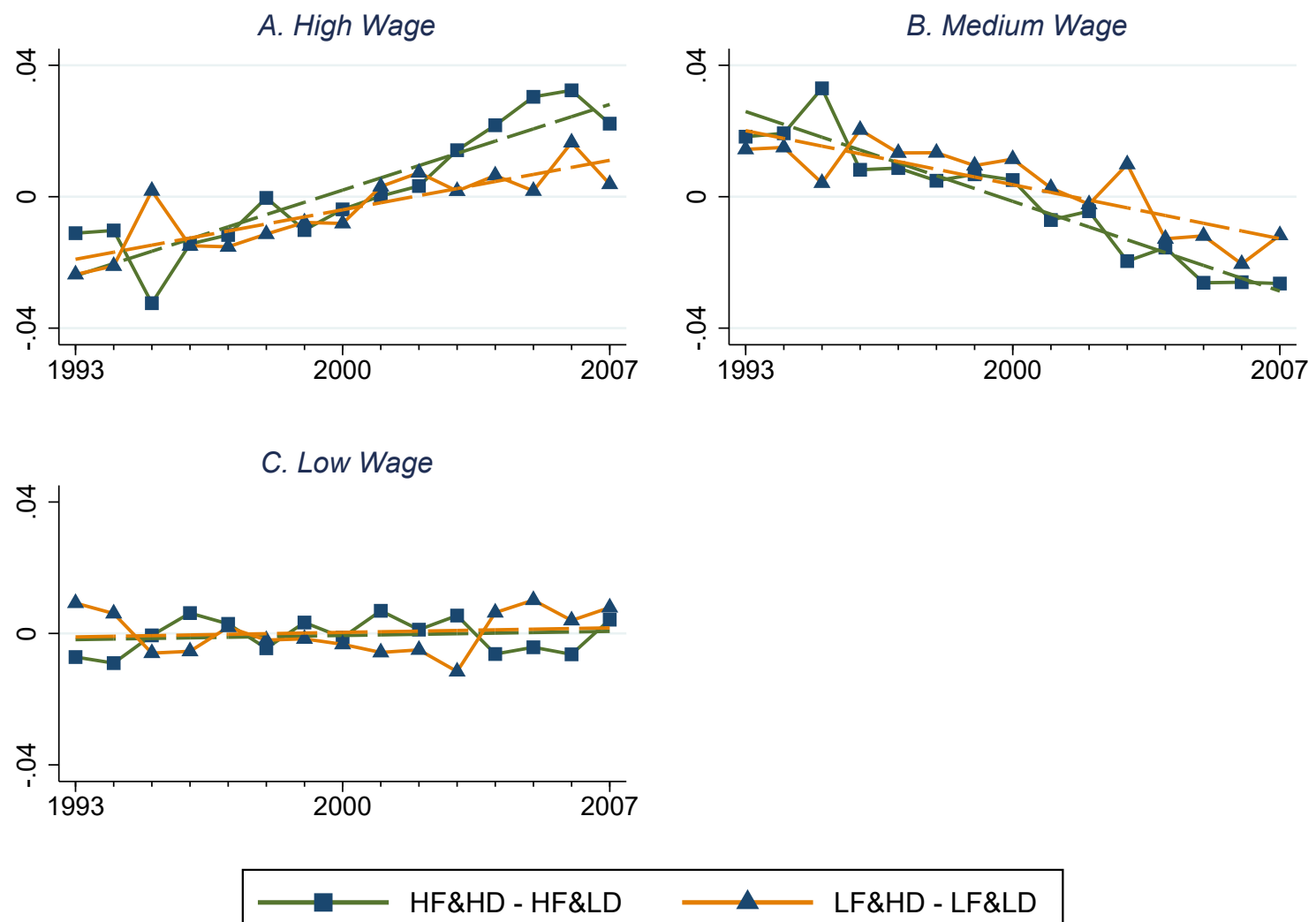

Note: This figure illustrates the differences in the trends of employment shares of high, medium and low wage occupations in industry-country pairs with high and low fall in IT prices and high and low IT dependence. The curves with square tick symbols are the difference between the employment shares in industries with high IT Dependence and industries with low IT Dependence among countries and years where and when the fall in IT Price is relatively high (HF\&HD - HF\&LD). The curves with triangle tick symbols are the difference between the employment shares in industries with high IT Dependence and industries with low IT Dependence among countries and years where and when the fall in IT Price is relatively low (LF\&HD - LF\&LD). The employment shares in this figure are the residuals from an OLS regression of employment shares on country-industry and country-year dummies. In each of the four groups, these shares are averaged over countries and industries. An industry has high (low) dependence on IT if its IT Dependence is above (below) the median IT Dependence across industries. For a given year, the fall in IT Price in a country-year pair is relatively high (low) if the fall in IT Price (relative to its previous level) in that pair is lower (higher) than the median change in IT Price across countries in that year. It is sufficient to compare countries according to the change in IT Price because IT Price has declined everywhere. See Table 6 in the Data Appendix for complete descriptions and sources of variables and for the assignment of occupations into high, medium and low wage groups. 


\section{Data Appendix}

Table 6: Definitions and Sources of Variables

\begin{tabular}{|c|c|}
\hline Variable Name & Definition and Source \\
\hline Capital Dependence & $\begin{array}{l}\text { The share of non-IT capital compensation out of value added in US indus- } \\
\text { tries, averaged over the period of 1993-2007. Source: EU KLEMS. }\end{array}$ \\
\hline Capital Price & $\begin{array}{l}\text { The price of investments in physical capital relative to the price of value } \\
\text { added in sample industries. It is averaged across industries, within countries } \\
\text { and years. I use the inverse of this measure in estimations. Source: EU } \\
\text { KLEMS. }\end{array}$ \\
\hline CT Price & $\begin{array}{l}\text { The price of investments in communication technologies relative to the price } \\
\text { of value added in sample industries. It is averaged across industries, in each } \\
\text { country and year. I use the inverse of this measure in estimations. Commu- } \\
\text { nication technologies include telephones, telephony related equipment, and } \\
\text { equipment to connect to the internet. Source: EU KLEMS. }\end{array}$ \\
\hline IT Dependence & $\begin{array}{l}\text { The share of IT capital compensation out of value added in US industries, } \\
\text { averaged over the period of 1993-2007. Source: Author's calculations using } \\
\text { data from EU KLEMS. }\end{array}$ \\
\hline IT Price & $\begin{array}{l}\text { The price of investments in information technologies relative to the price } \\
\text { of value added in sample industries }\left(p_{I T}\right) \text {. It is averaged across industries, } \\
\text { in each country and year. I use the inverse of this measure in estimations. } \\
\text { Information technologies include computers and machines which use and } \\
\text { depend on computers. Source: EU KLEMS. }\end{array}$ \\
\hline $\begin{array}{l}\text { Medium-Skill Depen- } \\
\text { dence }\end{array}$ & $\begin{array}{l}\text { The share of wage compensation of workers with medium-level of education } \\
\text { out of value added in US industries, averaged over the period of 1993-2007. } \\
\text { Medium-level of education corresponds to secondary to post-secondary and } \\
\text { non-tertiary education (3-4 of ISCED-97). Source: EU KLEMS. }\end{array}$ \\
\hline
\end{tabular}


Table 6 - (Continued)

Variable Name Definition and Source

Medium-Skill Wage The share of wage compensation of workers with medium-level of education

Rate out of total wage compensation in the industries of the sample Western European countries. Medium-level of education corresponds to secondary to post-secondary and non-tertiary education (3-4 of ISCED-97). Source: EU KLEMS.

Low-Skill Wage Rate The share of wage compensation of workers with low-level of education out of total wage compensation in the industries of the sample Western European countries. Low-level education corresponds to pre-primary to lower-secondary education (0-2 of ISCED-97). Source: EU KLEMS.

\begin{tabular}{ll}
\hline Group & Description \\
\hline Age Group & There are three age groups: young (between 15 and 30), medium-age (be- \\
& tween 30 and 45 ) and old (between 45 and 65$).$ \\
High IT Compensation & The industries that have IT compensation higher than the 75 percentile of \\
Industries & the distribution of IT compensation across industries within each sample \\
& country and year. Source: EU KLEMS. \\
Occupation & Occupations are grouped into three wage groups: high, medium and low \\
Group & wage. High wage occupations are ISCO-88 12, 13, 21, 22, 24, 31, 32 and 34. \\
& Medium wage occupations are ISCO-88 41, 42, 71, 72, 73, $74,81,82$ and \\
& 83. Low wage occupations are ISCO-88 51, 52, 91 and 93. See Table A in \\
& the Online Appendix - Tables and Figures for occupation names. Source: \\
& Goos et al. (2014).
\end{tabular}

Data Sources: December 2015 release of the EU Labour Force Survey database; March 2011 update of November 2009 release of the EU KLEMS database (and March 2008 release of the EU KLEMS database for Portugal).

Industry Sample (NACE rev. 1): D, E, F, G, H, I, J, K, N, and O. 


\section{Acknowledgements}

I would like to thank two anonymous referees, the editor, Jonathan Temple, as well as Matias Cortes, John S. Earle, Randall K. Filer, David Gomtsyan, Štěpán Jurajda, Anna Kochanova, Tobias Kretschmer, Anna Salomons, and participants at the AEA Meetings in Philadelphia (2018), the IBS Jobs Conference in Warsaw (2017), the IAW Conference in Tubingen (2017), the WPEG Conference in Sheffield (2017), the 31st ESPE Conference in Glasgow (2017), the 1st CES Conference in Barcelona (2017), the Workshop on Labour Economics in Trier (2017), the IZA BB Seminar in Bonn (2016), and the Armenian Economic Association Meetings in Yerevan (2016) for thoughtful comments. I gratefully acknowledge financial support from the Spanish Ministry of Education and Science through grant ECO2015-66701-R, from the Generalitat of Catalonia through grant 2014SGR493, and from the Grant Agency of the Czech Republic through project P402/12/G097. All errors remain my own.

\section{References}

Acemoglu, D. and Autor, D. H. (2011). Skills, tasks and technologies: Implications for employment and earnings, in: Ashenfelter, O. and Card, D. (Eds.) Handbook of Labor Economics, Vol. 4, Part B, Amsterdam, Netherlands: Elsevier, pp. 1043-1171.

Aum, S., Lee, S. Y. and Shin, Y. (2018). 'Computerizing industries and routinizing jobs: Explaining trends in aggregate productivity', Journal of Monetary Economics, Vol. 97, pp. 1-21.

Autor, D. H. and Dorn, D. (2009). "This job is "getting old": Measuring changes in job opportunities using occupational age structure', American Economic Review: Papers E Proceedings, Vol. 99, pp. 45-51.

Autor, D. H. and Dorn, D. (2013). 'The growth of low skill service jobs and the polarization of the U.S. labor market', American Economic Review, Vol. 103, pp. 1553-1597.

Autor, D. H., Katz, L. F. and Kearney, M. S. (2006). 'The polarization of the US labor market', American Economic Review, Vol. 96, pp. 189-194. 
Autor, D. H., Katz, L. F. and Kearney, M. S. (2008). 'Trends in US wage inequality: Revising the revisionists', Review of Economics and Statistics, Vol. 90, pp. 300-323.

Autor, D. H., Levy, F. and Murnane, R. J. (2003). 'The skill content of recent technological change: An empirical exploration', Quarterly Journal of Economics, Vol. 118, pp. 1279-1333.

Bárány, Z. L. and Siegel, C. (2018). 'Job polarization and structural change', American Economic Journal: Macroeconomics, Vol. 10, pp. 57-89.

Barone, G. and Cingano, F. (2011). 'Service regulation and growth: Evidence from OECD countries', Economic Journal, Vol. 121, pp. 931-957.

Beaudry, P. and Lewis, E. (2014). 'Do male-female wage differentials reflect differences in the return to skill? Cross-city evidence from 1980-2000', American Economic Journal: Applied Economics, Vol. 6, pp. 178-194.

Borghans, L., Weel, B. T. and Weinberg, B. A. (2014). 'People skills and the labormarket outcomes of underrepresented groups', Industrial \& Labor Relations Review, Vol. 67, pp. 287-334.

Cerina, F., Moro, A. and Rendall, M. (2017). The role of gender in employment polarization. CMF Discussion Paper No. 2017-04.

Chen, W., Niebel, T. and Saam, M. (2016). 'Are intangibles more productive in ICTintensive industries? Evidence from EU countries', Telecommunications Policy, Vol. 40, pp. $471-484$.

Cortes, G. M., Jaimovich, N. and Siu, H. E. (2018). The "end of men" and rise of women in the high-skilled labor market. NBER Working Paper No. 24274.

Deming, D. J. (2017). 'The growing importance of social skills in the labor market', Quarterly Journal of Economics, Vol. 132, pp. 1593-1640.

Gallipoli, G. and Makridis, C. A. (2018). 'Structural transformation and the rise of information technology', Journal of Monetary Economics, Vol. 97, pp. 91-110.

Goos, M. and Manning, A. (2007). 'Lousy and lovely jobs: The rising polarization of work in Britain', Review of Economics and Statistics, Vol. 89, pp. 118-133. 
Goos, M., Manning, A. and Salomons, A. (2009). 'Job polarization in Europe', American Economic Review: Papers \& Proceedings, Vol. 99, pp. 58-63.

Goos, M., Manning, A. and Salomons, A. (2014). 'Explaining job polarization: Routinebiased technological change and offshoring', American Economic Review, Vol. 104, pp. $2509-2526$.

Jerbashian, V. and Kochanova, A. (2016). 'The impact of doing business regulations on investments in ICT', Empirical Economics, Vol. 50, pp. 991-1008.

Jerbashian, V. and Kochanova, A. (2017). 'The impact of telecommunication technologies on competition in services and goods markets: Empirical evidence', Scandinavian Journal of Economics, Vol. 119, pp. 628-655.

Kambourov, G. and Manovskii, I. (2009). 'Occupational specificity of human capital', International Economic Review, Vol. 50, pp. 63-115.

Katz, L. F. and Autor, D. H. (1999). Changes in the wage structure and earnings inequality, in: Ashenfelter, O. and Card, D. (Eds.) Handbook of Labor Economics, Vol. 3, Part A, Amsterdam, Netherlands: Elsevier, pp. 1463-1555.

Krusell, P., Ohanian, L. E., Ríos-Rull, J.-V. and Violante, G. L. (2000). 'Capital-skill complementarity and inequality: A macroeconomic analysis', Econometrica, Vol. 68, pp. 1029-1053.

Mazzolari, F. and Ragusa, G. (2013). 'Spillovers from high-skill consumption to low-skill labor markets', Review of Economics and Statistics, Vol. 95, pp. 74-86.

Melhem, S., Morrell, C. and Tandon, N. (2009). Information and communication technologies for womens socioeconomic empowerment. World Bank Working Papers No. 176.

Michaels, G., Natraj, A. and van Reenen, J. (2014). 'Has ICT polarized skill demand? Evidence from eleven countries over twenty-five years', Review of Economics and Statistics, Vol. 96, pp. 60-77.

O’Mahony, M. and Timmer, M. P. (2009). 'Output, input and productivity measures at the industry level: The EU KLEMS database', Economic Journal, Vol. 119, pp. F374-F403. 
Rajan, R. G. and Zingales, L. (1998). 'Financial dependence and growth', American Economic Review, Vol. 88, pp. 559-586.

United Nations (2005). Gender equality and empowerment of women through ICT. Women2000 and Beyond. 


\title{
Online Appendix to "Automation and Job Polarization: On the Decline of Middling Occupations in Europe"
}

\author{
Vahagn Jerbashian*
}

\section{A Online Appendix - Further Robustness Checks and Results}

This section presents the results from further robustness check exercises. It also offers additional results. I conduct robustness checks with respect to the sample of years, industries, and countries, identifying assumptions and variation in the data, and measures.

Figure 2 suggests that there can be differences in the trends of employment before and after 2001. I estimate the specification (10) restricting sample period to 1993-2001 and present the results in Panel $A$ of Table B. Import competition can matter for employment shares in high, medium and low wage occupations (Autor, Dorn, and Hanson, 2015). Panel $B$ of Table B reports the results when I exclude from the sample Manufacturing, the tradable industry. All of these results are qualitatively no different from the main results offered in Panel $A$ of Table 4.

The measure of IT dependence is defined as the share of IT capital compensation in US industries out of value added, averaged over the sample period. Around 90 percent of the variation in the share of IT capital compensation in US industries is at industry level according to Table E. Therefore, this measure is likely to identify technological differences across industries. However, this measure of dependence would be valid for the current exercise if US industries are technologically similar to the industries of the sample Western

\footnotetext{
*University of Barcelona, BEAT, and CERGE-EI. Correspondence address: Av. Diagonal 696, 08034 Barcelona, Spain. E-mail: vahagn.jerbashian@ub.edu. Phone: +34934034890.

CERGE-EI is a joint workplace of the Center for Economic Research and Graduate Education, Charles University in Prague, and the Economics Institute of Academy of Sciences of the Czech Republic.
} 
European countries. This seems to be the case according to the correlations reported in Table 1.

In order to alleviate potential concerns, I use data from the sample Western European countries to construct an alternative measure of dependence on information technologies, IT Dependence EU. IT Dependence EU is defined as the share of IT capital compensation out of value added in industries of the sample Western European countries, averaged over the sample countries and period. The correlation between this measure and the main measure of dependence is $0.944 .^{2}$ I estimate the specification (10) with this measure and report the results in Panel $A$ of Table $\mathrm{C}$. These are qualitatively no different from the main results.

According to equation (2), industry-level variation in factor input levels can affect the values of IT Dependence. This can bias the coefficient on the interaction term in the specification (10) in a non-trivial manner. In order to alleviate potential concerns, I make use of the fact that it is sufficient to have a correct ranking of industries according to their dependence on IT. Chen et al. (2016) and Jerbashian and Kochanova (2016, 2017) utilize similar measures of dependence on information and communication technologies, and rank correlations of IT Dependence with their measures are very high. I rank sample industries according to the value of IT Dependence using positive, equidistant weights which sum to one. I call this ranking IT Dependence RW and use it is a measure of dependence in the specification (10). The results with this measure reaffirm the main results and are reported in Panel $B$ of Table $\mathrm{C}$.

I use the prices of information technologies to analyze the effects of recent technological changes on employment. This involves trade-offs. The prices of information technologies are usually better measured and constructed under less strict assumptions than the series of capital, for example. The variation of prices is more likely to reflect exogenous technical changes than the variation in investment and capital series because the latter entail an additional margin of decision making. However, the series of prices of information technologies might not fully reflect the actual technological change in IT and the adoption

\footnotetext{
${ }^{2}$ According to Table $\mathrm{F}$, industry-level variation explains more than 50 percent of the variation of the share of IT compensation out of value added in industries of the sample Western European countries.
} 
of new information technologies. In Panel $C$ of Table $\mathrm{C}$, I use real investments in IT relative to real value added in sample industries (IT Investments), instead of $1 /$ IT Price, in order to alleviate such concerns. ${ }^{3}$ The estimate on the interaction term is significant and positive for the share of employment in high wage occupations. It is negative for the share of employment in medium wage occupations. These results corroborate the hypothesis for job polarization. They suggest that, as investments in IT have grown, industries which depend more on IT have increased the demand for high wage occupations and reduced the demand for medium wage occupations more than industries which depend less.

Left-hand side variables in all regressions are shares and are between 0 and 1 . I estimate the specification (10) using Tobit with $(0,1)$ censoring. Panel $A$ of Table D summarizes the results. These are almost identical to the main results.

I also estimate the specification (10) for all NACE 1-digit industries for which there are data in the ELFS and EU KLEMS databases. Panel $B$ of Table D reports the results, which are very close to the main results.

\section{Not Reported Robustness Checks and Results}

I continue performing robustness checks, but do not report the results for brevity. Offshoring can matter for employment shares according to Goos, Manning, and Salomons (2014), although its effect in industries with different levels of dependence on IT is not clear a priori. To check whether offshoring can affect the results, I exclude from the analysis occupations which have offshorability score higher than the 75 th percentile of offshorability index offered by Goos et al. (2014). Excluding these occupations does not have any significant effect on the results.

In the main text, I compute employment shares in industry-occupation pairs using (usual) weekly hours worked. I have checked that the results are robust to using the number of persons employed instead of the number of hours.

The possible changes of employment in manual tasks are disregarded in equation (6).

\footnotetext{
${ }^{3}$ The correlation between IT Investments and the price of information technologies relative to the price of value added (IT Price Ind) is -0.381 and is significant at the $1 \%$ level. IT Price Ind has large temporal variation, relatively small variation across countries, and almost no variation across industries according to Table G
} 
As a robustness check, I compute industry-level employment as a sum of employment in high and medium wage occupations and compute employment shares in industryoccupation pairs using this measure of employment. The results which I obtain are very similar to the main results for high and medium wage occupations.

An alternative way of measuring the dependence on IT uses the share of IT compensation of the industries of the sample Western European countries and allows it to vary across years and countries. Another alternative measure predicts IT Dependence EU using the measure identified with US data, IT Dependence. I use these alternative measures and obtain results very similar to the main results. I also obtain reaffirming results when I use the main dependence measure on information and communication technologies of Chen, Niebel, and Saam (2016). Moreover, the results are robust to using the sample initial value of the share of IT capital compensation out of value added in US industries as a dependence measure. Standard errors are somewhat inflated with this measure, however, which can be because of a higher amount of noise.

A flexible way of controlling for possible trends and differences in initial values is to include the lagged dependent variable in the regression. I do so and obtain results which are qualitatively similar to the main results. ${ }^{4}$

In the main text, the coefficient of interest $\beta$ is identified from within country temporal variation of 1/IT Price, industry-level variation of IT Dependence, and within country-industry-year-level variation of the interaction term. As a robustness check, I disregard country-level variation taking the averages of the shares of employment and 1/IT Price across countries and estimating a version of specification (10) with industry and year dummies. I obtain results which are similar to the main results, though the inference regarding the differences across gender is somewhat weaker. I also estimate the specification (10) with a full set of industry-year dummies instead of industry group-year dummies as in Panel $E$ of Table 5. In this exercise, $\beta$ is identified from within country, industry, and year variation, which disregards the significant and omnipresent advances in information technologies over time. I obtain results which are qualitatively similar to

\footnotetext{
${ }^{4}$ This exercise might be taken with a caution because of the fixed effects estimation and the resulting mechanical endogeneity of the lagged dependent variable.
} 
the main results, though the estimates of $\beta$ are insignificant and relatively small. The estimates of $\beta$ become significant and very close to the main results when I drop from the sample Southern European countries Italy, Portugal, and Spain, which have very rigid labor and product markets.

There can be problems with the kinkiness of the data which can be observed for some occupation groups. I fit third order polynomials on the shares of employment in each occupation group-industry-country triple using time variation. I use these polynomials in the estimation of the specification (10). The results that I obtain are similar to the main results. I also drop the first and the last percentiles of the distribution of employment shares in each country. Again, the results are close to the main results.

I use the March 2011 update of the November 2009 release of the EU KLEMS database for all countries except Portugal. For Portugal, I use the March 2008 release of the EU KLEMS database. I exclude Portugal from the sample of counties and obtain results which are similar to the main results. In the ELFS and EU KLEMS databases there is information for the Czech Republic and Slovenia. I include these countries in the analysis. This does not effect the results.

I use all the available temporal variation in order to identify $\beta$. This allows to fully utilize the significant and omnipresent advances in information technologies over the sample period. I also attempt to estimate $\beta$ using long differences. I take the differences between sample initial and end values in industry-country pairs in the specification (10) and estimate it for those differences including industry-fixed effects in it. This exercise provides estimates of $\beta$ which have the same sign as the main estimates, but are not statistically significant. A reason for this is that taking long differences reduces the number of observations by about 10 times.

I perform all these robustness checks for the shares of employment in high, medium and low wage occupations within gender and age groups. I obtain results which are similar to the main findings.

The number of observations has a small variation in samples which I use for estimations for gender and age groups. I check that all the results hold in case the panels are 
restricted to be the same.

There have been country-level changes in employment composition of genders and age groups in high, medium and low wage occupations. Such compositional changes can confound the results if they are more pronounced in industries with higher $\alpha_{I T}$ and are not because of the fall in IT Price, but are correlated with it. To rule out such an explanation, I include an interaction of Industry Dependence and the country-level share of employment in the corresponding occupation group among gender and age groups in the specification (10). I obtain results which are qualitatively similar to the main findings.

Trends in female labor supply can confound the results for that group and the identified differences between genders. This concern is somewhat alleviated with the test showing that the results are robust to the inclusion of lagged dependent variable in the regression. I also obtain estimates of $\beta$, which are very similar to the estimates in Panel $C$ of Table 4, when I estimate the specification (10) using data for the year 2000 and after. In this period, trends in female labor supply are much less pronounced. Cerina, Moro, and Rendall (2017) show that polarization trends in female labor supply are more pronounced among married females than among not married females. I check that the estimates of $\beta$ are very close the estimates in Panel $C$ of Table 4 , when I estimate the specification (10) for married, as well as not married, females.

There can be differences in intensive and extensive margins of adjustment of employment among males and females. The EU LFS database is a repeated cross-section, and one way to check this tests whether the results are different from the main results in Panels $B$ and $C$ of Table 4 among young males and among young females (age from 15 to 30). I find that the results for young males and among young females are not different from the main results.

\section{Education-level Groups}

I retrieve information from the ELFS database on the levels of education to check that the results for within education-level groups are similar to the main results in Panel $A$ of Table 4. There are three levels of education in this database: pre-primary to lower-secondary 
(low; ISCED-97 0-2), secondary to post-secondary and non-tertiary (medium; ISCED-97 3-4) and tertiary (high; ISCED-97 5-6). I compute the number of hours worked in each of these education-level groups for all occupation group-industry cells in sample countries and years and the share of employment in high, medium and low wage occupations within these groups.

I estimate the specification (10) for the shares of employment in high, medium and low wage occupations within education-level groups. Similarly to the main results, the fall in IT prices has increased the share of employment in high wage occupations, reduced the share of employment in medium wage occupations, and has had no robust effect on the share of employment in low wage occupations within these groups. Moreover, the effect of the fall in IT prices on employment shares of medium-educated workers in high and medium wage occupations is about twice as much as on employment shares among highly educated and low-educated workers.

Michaels, Natraj, and van Reenen (2014) use US data to argue that medium-educated (medium-skill) workers tend to be the most specialized in routine-intensive tasks. Their argument suggests that medium-educated workers have the highest $\alpha_{T_{R}}$. Admittedly, it might seem somewhat surprising then that the fall in IT prices has had a larger effect on medium-educated workers from the lens of the theoretical model presented in the main text. This can warrant a further investigation. It suggests that either the theoretical model might not be very well suited for explaining differences in the results for low-, medium- and highly educated workers or the correspondence between education levels and occupation/task groups is weaker in European countries than in the US. The next section provides suggestive evidence for the latter.

The results from all not reported robustness checks are available upon request. 


\section{B Online Appendix - Education Levels in Occupa- tion Groups}

Michaels et al. (2014) offer evidence from 11 developed countries (including Western European countries) that information and communication technologies (ICT) have changed skill demand. According to their findings, these technologies have increased the demand for highly educated workers at the expense of the demand for medium-educated workers. Michaels et al. (2014) argue that their results stem from a firm correspondence between education levels and employment in high, medium and low wage occupations groups and tasks performed in these occupation groups. In particular, they use US data to offer evidence that the fraction of highly educated workers is the highest in high wage occupations and, similarly, the fractions of medium- and low-educated workers are the highest in medium and low wage occupations, correspondingly.

This evidence motivates my use of the share of wage compensation of mediumeducated workers out of value added in US industries as a proxy for $\alpha_{T_{R}}$. It also motivates my use of the wage compensations of medium- and low-educated workers as proxies for the compensations of workers in medium and low wage occupations. Nevertheless, I show below that the latter two proxies might be taken with some caution. The firm correspondence argued by Michaels et al. (2014) is not straightforward to replicate for occupations groups, industry aggregates, and the sample of European countries, which I use.

Table $\mathrm{H}$ reports education levels within high, medium and low wage occupations averaged over sample countries, industries, and years. The shares of workers with highand medium-level of education within high wage occupations are almost identical. The average share of workers with medium-level of education is the highest within medium wage occupations. However, this average is not statistically significantly different from the average share of workers with low-level of education in medium wage occupations. The shares of workers with medium- and low-level of education within low wage occupations are almost identical. Nevertheless, there are very few workers with low-level of education in high wage occupations and highly educated workers in medium and low 
wage occupations.

Table I reports correlations between wage rates of highly, medium and low educated workers and employment shares in high, medium and low wage occupations. The correlation between high-skill wage rate and employment share in high wage occupations is positive. Similarly, the correlations between medium-skill and low-skill wage rates and employment shares in medium and low wage occupations are positive. Taken together, this evidence suggests that there is a correspondence between education levels and wage/occupation groups in European countries. However, it is not a very strong one. 
C Online Appendix - Tables and Figures 


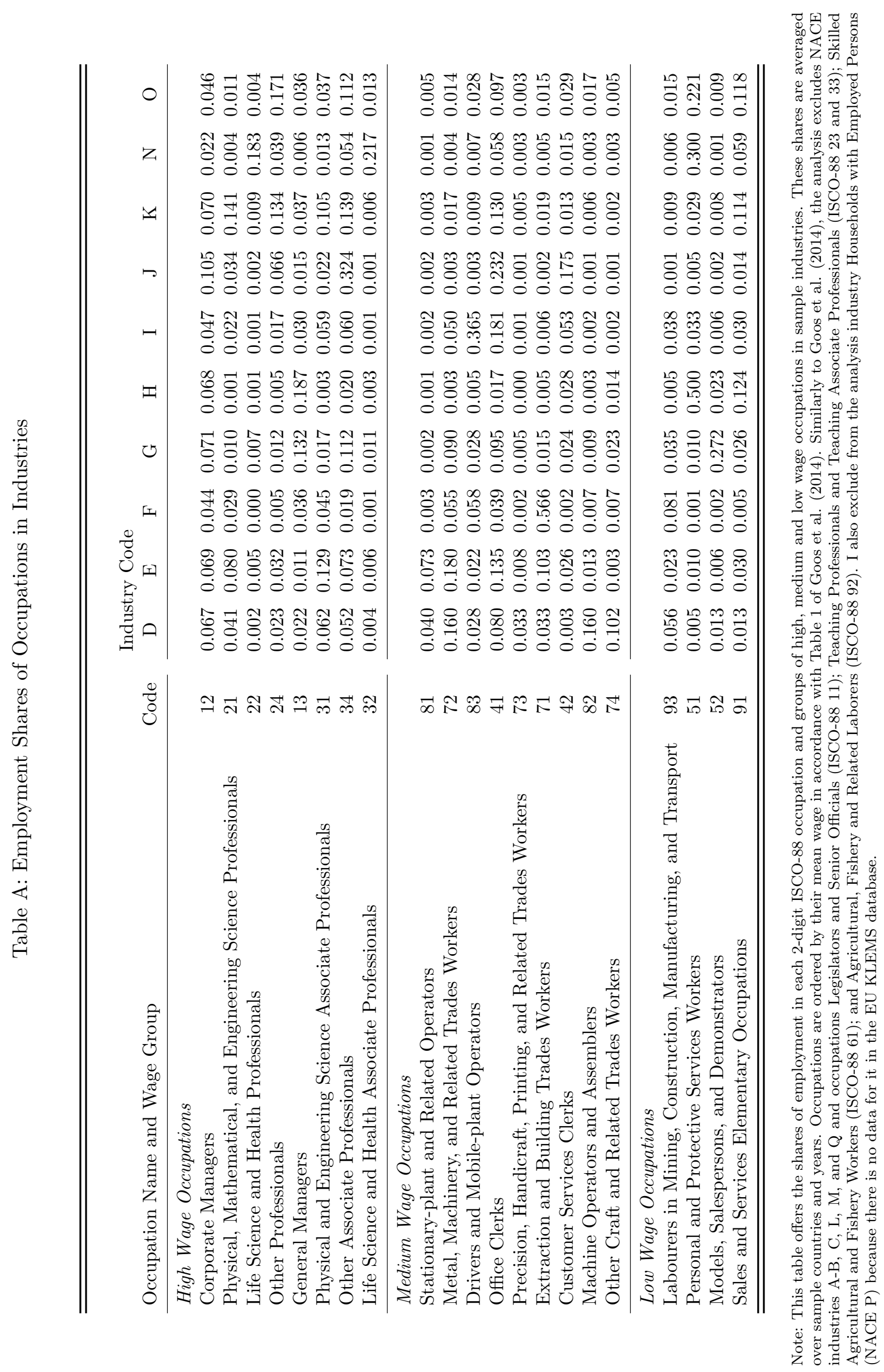


Table B: Robustness Checks - Sample Restrictions

\begin{tabular}{|c|c|c|c|c|c|c|}
\hline & High Wage & Medium Wage & Low Wage & High Wage & Medium Wage & Low Wage \\
\hline & \multicolumn{3}{|c|}{ A. Sample Period Till 2001} & \multicolumn{3}{|c|}{ B. W/o Tradeable Industries } \\
\hline $\begin{array}{l}\text { IT Dependence } \\
\times 1 / \text { IT Price }\end{array}$ & $\begin{array}{c}(1) \\
0.211^{* * *} \\
(0.062)\end{array}$ & $\begin{array}{c}(2) \\
-0.170^{* * *} \\
(0.060)\end{array}$ & $\begin{array}{c}(3) \\
-0.041 \\
(0.032)\end{array}$ & $\begin{array}{c}(1) \\
0.217^{* * *} \\
(0.026)\end{array}$ & $\begin{array}{c}(2) \\
-0.213^{* * *} \\
(0.025)\end{array}$ & $\begin{array}{c}(3) \\
-0.004 \\
(0.018)\end{array}$ \\
\hline Obs & 780 & 780 & 780 & 1,224 & 1,224 & 1,224 \\
\hline R2 (Partial) & 0.035 & 0.031 & 0.002 & 0.087 & 0.133 & 0.000 \\
\hline \multicolumn{7}{|c|}{$\begin{array}{l}\text { Note: This table offers the results from the estimation of the specification }(10) \text { for the shares of employment in high, } \\
\text { medium and low wage occupations. The dependent variable is employment share in the corresponding occupation group } \\
\text { within industry-country-year cells. Panel } A \text { offers the results from the estimation of the specification (10) where years } \\
\text { after } 2001 \text { are excluded from the sample. In Panel } A \text {, IT Dependence is defined as the share if IT capital compensation } \\
\text { out of value added in US industries, averaged over } 1993-2001 \text {. In Panel } B \text {, tradeable industries (Manufacturing, NACE D) } \\
\text { are excluded from the sample. See Table } 6 \text { in the Data Appendix for complete descriptions and sources of variables. All } \\
\text { regressions include country-industry and country-year dummies and and use the least squares estimation method. Standard } \\
\text { errors are in parentheses. Standard errors are bootstrapped and two-way clustered at industry-and country-year-level. R2 } \\
\text { (Partial) is the R-squared of the model where country-industry and country-year dummies have been partialled out. *** } \\
\text { indicates significance at the } 1 \% \text { level, } * * \text { at the } 5 \% \text { level, and } * \text { at the } 10 \% \text { level. }\end{array}$} \\
\hline
\end{tabular}




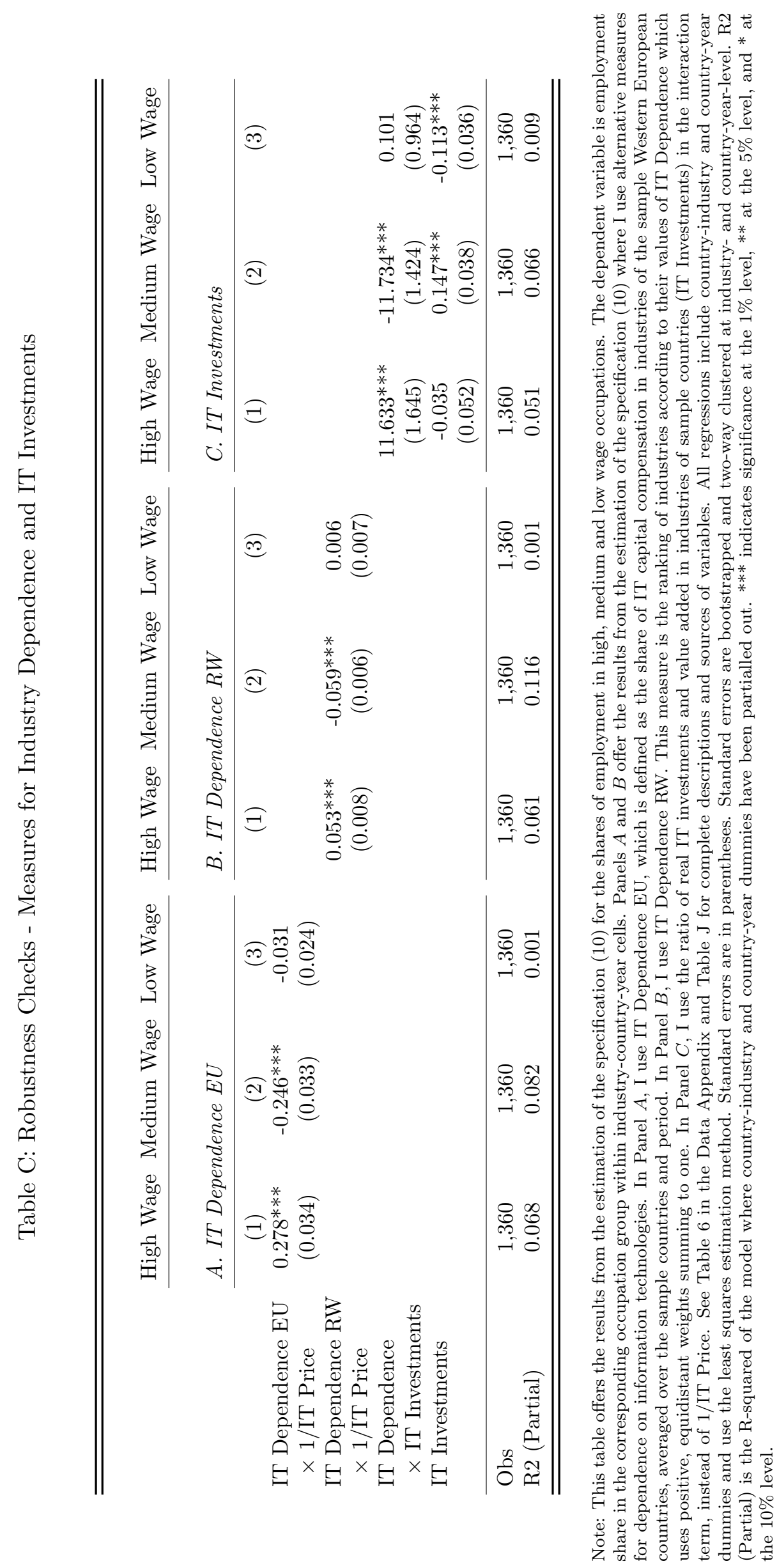


Table D: Robustness Checks - Tobit and All Industries

\begin{tabular}{|c|c|c|c|c|c|c|}
\hline & High Wage & Medium Wage & Low Wage & High Wage & Medium Wage & Low Wage \\
\hline & \multicolumn{3}{|l|}{ A. Tobit } & \multicolumn{3}{|c|}{ B. All Industries } \\
\hline $\begin{array}{l}\text { IT Dependence } \\
\times 1 / \text { IT Price }\end{array}$ & $\begin{array}{c}(1) \\
0.217^{* * *} \\
(0.025)\end{array}$ & $\begin{array}{c}(2) \\
-0.212^{* * *} \\
(0.025)\end{array}$ & $\begin{array}{c}(3) \\
-0.005 \\
(0.018)\end{array}$ & $\begin{array}{c}(1) \\
0.204^{* * *} \\
(0.029)\end{array}$ & $\begin{array}{c}(2) \\
-0.207^{* * *} \\
(0.024)\end{array}$ & $\begin{array}{c}(3) \\
0.003 \\
(0.015)\end{array}$ \\
\hline $\begin{array}{l}\text { Obs } \\
\text { R2 (Partial) }\end{array}$ & 1,360 & 1,360 & 1,360 & $\begin{array}{l}1,895 \\
0.040\end{array}$ & $\begin{array}{l}1,895 \\
0.057\end{array}$ & $\begin{array}{l}1,895 \\
0.000\end{array}$ \\
\hline
\end{tabular}

Note: This table offers the results from the estimation of the specification (10) for the shares of employment in high, medium and low wage occupations. The dependent variable is employment share in the corresponding occupation group within industry-country-year cells. Panel $A$ offers the results from the estimation of the specification (10) using Tobit with $(0,1)$ censoring. In Panel $B$, I add Agriculture, Hunting, and Fishing (NACE A-B), Mining and Quarrying (NACE C), Public Administration; Social Security (NACE L), Education (NACE M), and Extra-territorial Organizations and Bodies (NACE Q) to the sample of industries. See Table 6 in the Data Appendix and Table J for complete descriptions and sources of variables. All regressions include country-industry and country-year dummies. Standard errors are in parentheses. Standard errors are clustered at industry-level in Panel A. The estimation method is least squares in Panel $B$, and standard errors are bootstrapped and two-way clustered at industry- and country-year-level. R2 (Partial) is the Rsquared of the model where country-industry and country-year dummies have been partialled out. ${ }^{* * *}$ indicates significance at the $1 \%$ level, ** at the $5 \%$ level, and * at the $10 \%$ level.

Table E: ANOVA for the Share of IT Compensation in US Industries

\begin{tabular}{lccc}
\hline \hline Source & Partial SS & df & MS \\
\hline Total & 0.037 & 149 & 0.000 \\
& & & \\
Industry & 0.033 & 9 & 0.004 \\
Year & 0.001 & 14 & 0.000 \\
Industry $\times$ Year & 0.002 & 126 & 0.000 \\
\hline \hline
\end{tabular}

Note: This table reports the results from an ANOVA exercise for the share of IT compensation of US industries out of value added. The variation in the data are at industry-year level, and I perform ANOVA along each of these dimensions. The number of observations is $150, \mathrm{RMSE}=0$. 
Table F: ANOVA for the Share of IT Compensation in Industries of Sample Countries

\begin{tabular}{lccc}
\hline \hline & & & \\
Source & Partial SS & df & MS \\
\hline Total & 0.290 & 1359 & 0.000 \\
& & & \\
Industry & 0.150 & 9 & 0.017 \\
Country & 0.042 & 9 & 0.005 \\
Industry $\times$ Country & 0.062 & 81 & 0.001 \\
Year & 0.005 & 14 & 0.000 \\
Year $\times$ Industry & 0.008 & 126 & 0.000 \\
Year $\times$ Country & 0.005 & 112 & 0.000 \\
Year $\times$ Industry $\times$ Country & 0.018 & 1008 & 0.000 \\
\hline \hline
\end{tabular}

Note: This table reports the results from an ANOVA exercise for the share of IT compensation in industries of the sample Western European countries out of value added. The variation in the data are at industry-country-year level, and I perform ANOVA along each of these dimensions. The number of observations is $1360, \mathrm{RMSE}=0$.

Table G: ANOVA for IT Price Ind

\begin{tabular}{lccc}
\hline \hline & & & \\
Source & Partial SS & df & MS \\
\hline Total & 186.629 & 1359 & 0.137 \\
& & & \\
Industry & 0.498 & 9 & 0.055 \\
Country & 9.717 & 9 & 1.080 \\
Industry $\times$ Country & 0.656 & 81 & 0.008 \\
Year $\times$ Industry & 170.875 & 14 & 12.205 \\
Year $\times$ Country & 0.278 & 126 & 0.002 \\
Year $\times$ Country & 2.865 & 112 & 0.026 \\
Year $\times$ Industry $\times$ Coun & 0.555 & 1008 & 0.001 \\
\hline \hline
\end{tabular}

Note: This table reports the results from an ANOVA exercise for the price of information technologies relative to the price of value added (IT Price Ind). The variation in the data are at industry-country-year level, and I perform ANOVA along each of these dimensions. The number of observations is 1360, RMSE $=0$. See Table 6 in the Data Appendix and Table $\mathrm{J}$ for complete descriptions and sources of variables. 
Table H: Shares of Education Levels in High, Medium and Low Wage Occupations

\begin{tabular}{|c|c|c|c|c|c|c|}
\hline $\begin{array}{l}\text { Education } \\
\text { Level }\end{array}$ & $\begin{array}{l}\text { Occupation } \\
\text { Group }\end{array}$ & Obs & Mean & $\mathrm{SD}$ & Min & Max \\
\hline High & High Wage & 1338 & 0.415 & 0.201 & 0.016 & 0.943 \\
\hline Medium & & 1338 & 0.417 & 0.180 & 0.034 & 0.858 \\
\hline Low & & 1338 & 0.168 & 0.166 & 0.000 & 0.900 \\
\hline High & Medium Wage & 1334 & 0.111 & 0.093 & 0.000 & 0.599 \\
\hline Medium & & 1334 & 0.537 & 0.203 & 0.031 & 0.939 \\
\hline Low & & 1334 & 0.352 & 0.214 & 0.005 & 0.967 \\
\hline High & Low Wage & 1204 & 0.065 & 0.053 & 0.000 & 0.588 \\
\hline Medium & & 1204 & 0.437 & 0.196 & 0.017 & 0.900 \\
\hline Low & & 1204 & 0.498 & 0.207 & 0.014 & 0.981 \\
\hline
\end{tabular}

Note: This table offers basic statistics for the shares of workers with high-, medium- and low-level of education within high, medium and low wage occupations in sample industries, countries, and years. There is a variation in the number of observations within wage/occupation groups. The results are almost identical to the results reported above when the sample is restricted to a balanced panel for all wage groups. The results also almost identically repeat for each year in the sample. See Table 6 in the Data Appendix for complete descriptions and sources of variables.

Table I: Correlations between Wage Rates and Employment Shares

\begin{tabular}{lcccccc}
\hline \hline & & & & & \\
& 1 & 2 & 3 & 4 & 5 \\
\hline 1. High-Skill Wage Rate & & & & & \\
2. Medium-Skill Wage Rate & -0.691 & & & & \\
3. Low-Skill Wage Rate & -0.133 & -0.625 & & & \\
4. Employment Share in High Wage Occupations & 0.594 & -0.227 & -0.331 & & \\
5. Employment Share in Medium Wage Occupations & -0.353 & 0.176 & 0.140 & -0.567 & \\
6. Employment Share in Low Wage Occupations & -0.092 & -0.014 & 0.120 & -0.195 & -0.697 \\
\hline \hline
\end{tabular}

Note: This table report pairwise correlations for compensations of high-, medium- and low-skill eomployees relative to value added and employment shares in high, medium and low wage occupations. The variation in the data are at industrycountry-year level. The correlation between medium-skill wage rate and employment share in low wage occupations is insignificant at any conventional level of significance. All remaining correlations are significant at $1 \%$ significance level. 
Figure A: Employment Shares in High, Medium and Low Wage Occupations in Sample Countries

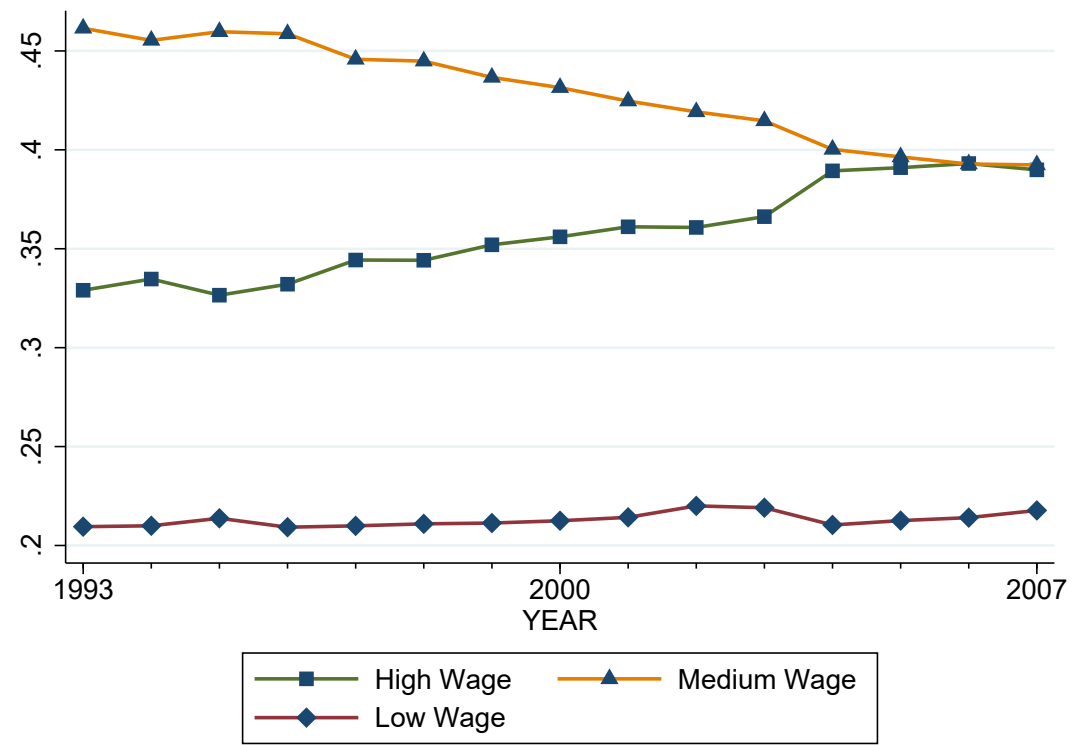

Note: This figure illustrates the trends in the shares of employment in high, medium and low wage occupation groups. These employment shares are averaged over the sample countries. See Table 6 in the Data Appendix for the assignment of occupations into high, medium and low wage groups. 
Figure B: Employment Shares in High, Medium and Low Wage Occupations in High and Low IT Dependence Industries within Genders
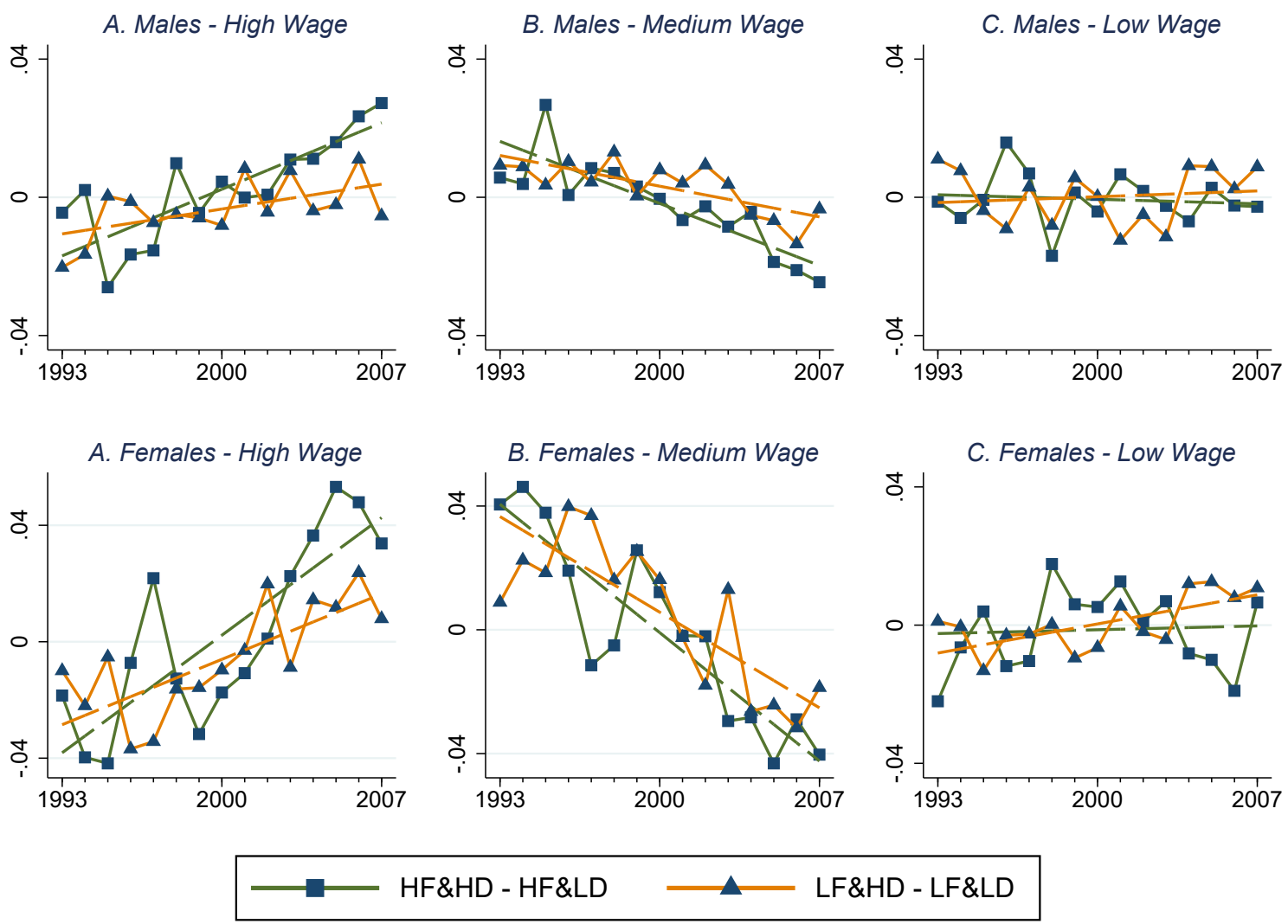

Note: This figure illustrates the differences in the trends of employment shares of high, medium and low wage occupations within genders in industry-country pairs with high and low fall in IT prices and high and low IT dependence. The curves with square tick symbols are the difference between the employment shares within genders in industries with high IT Dependence and industries with low IT Dependence among countries and years where and when the fall in IT Price is relatively high (HF\&HD - HF\&LD). The curves with triangle tick symbols are the difference between the employment shares within genders in industries with high IT Dependence and industries with low IT Dependence among countries and years where and when the fall in IT Price is relatively low (LF\&HD - LF\&LD). The employment shares in this figure are the residuals from an OLS regression of employment shares on country-industry and country-year dummies. In each of the four groups, these shares are averaged over countries and industries. An industry has high (low) dependence on IT if its IT Dependence is above (below) the median IT Dependence across industries. For a given year, the fall in IT Price in a country-year pair is relatively high (low) if the fall in IT Price (relative to its previous level) in that pair is lower (higher) than the median change in IT Price across countries in that year. It is sufficient to compare countries according to the change in IT Price because IT Price has declined everywhere. See Table 6 in the Data Appendix for complete descriptions and sources of variables. See Table 6 in the Data Appendix for the assignment of occupations into high, medium and low wage groups. 
Figure C: Employment Shares in High, Medium and Low Wage Occupations in High and Low IT Dependence Industries within Age Groups

A. Young - High Wage

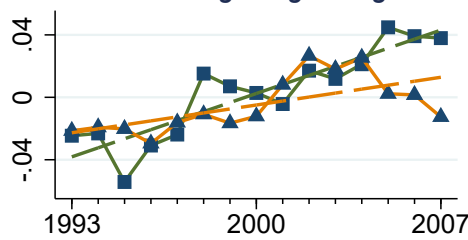

D. Medium-Age - High Wage

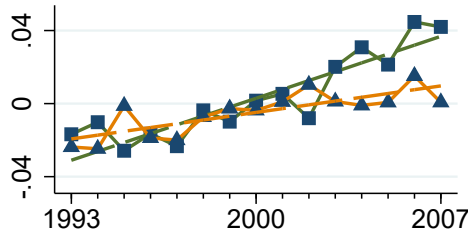

G. Old - High Wage

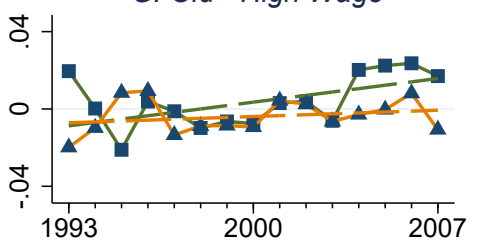

B. Young - Medium Wage

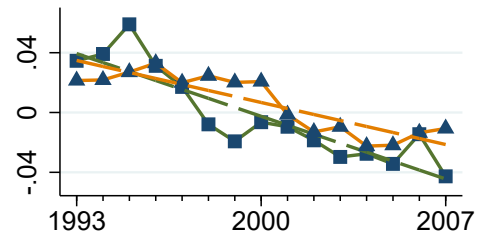

E. Medium-Age - Medium Wage

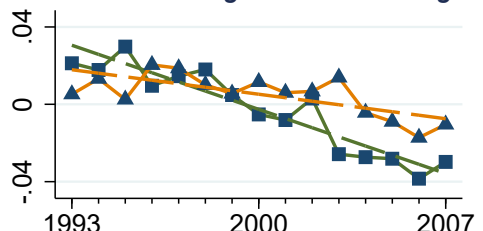

H. Old - Medium Wage

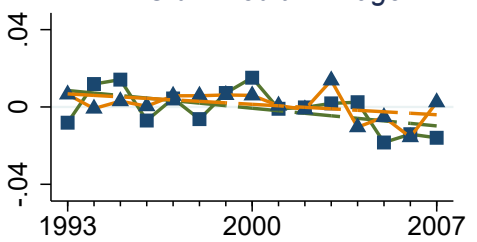

C. Young - Low Wage

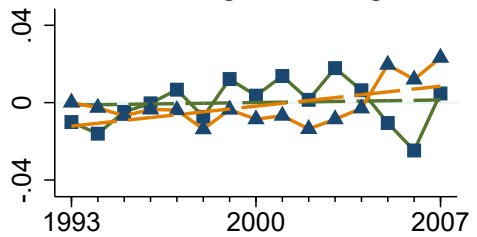

F. Medium-Age - Low Wage
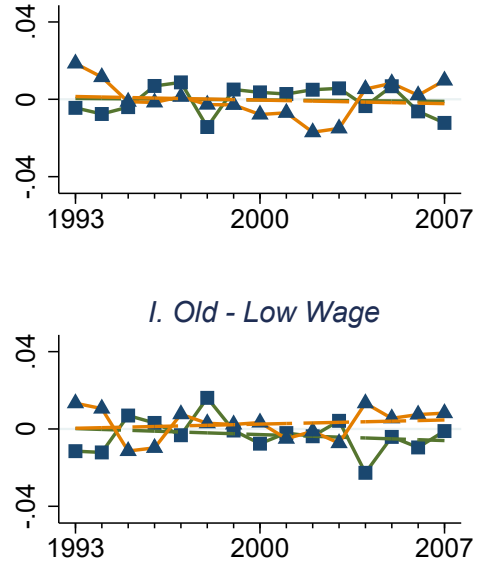

Note: This figure illustrates the differences in the trends of employment shares of high, medium and low wage occupations within age groups in industry-country pairs with high and low fall in IT prices and high and low IT dependence. The curves with square tick symbols are the difference between the employment shares within age groups in industries with high IT Dependence and industries with low IT Dependence among countries and years where and when the fall in IT Price is relatively high (HF\&HD - HF\&LD). The curves with triangle tick symbols are the difference between the employment shares within age groups in industries with high IT Dependence and industries with low IT Dependence among countries and years where and when the fall in IT Price is relatively low (LF\&HD - LF\&LD). The employment shares in this figure are the residuals from an OLS regression of employment shares on country-industry and country-year dummies. In each of the four groups, these shares are averaged over countries and industries. An industry has high (low) dependence on IT if its IT Dependence is above (below) the median IT Dependence across industries. For a given year, the fall in IT Price in a country-year pair is relatively high (low) if the fall in IT Price (relative to its previous level) in that pair is lower (higher) than the median change in IT Price across countries in that year. It is sufficient to compare countries according to the change in IT Price because IT Price has declined everywhere. See Table 6 in the Data Appendix for complete descriptions and sources of variables. See Table 6 in the Data Appendix for the assignment of occupations into high, medium and low wage groups. 
Table J: Additional Definitions and Sources of Variables

\begin{tabular}{|c|c|}
\hline Variable Name & Definition and Source \\
\hline IT Dependence EU & $\begin{array}{l}\text { The share of IT capital compensation out of value added in the industries } \\
\text { of sample Western European countries, averaged over sample countries } \\
\text { and period. Source: Author's calculations using data from EU KLEMS. }\end{array}$ \\
\hline IT Dependence RW & $\begin{array}{l}\text { I rank sample industries according to their values of IT Dependence using } \\
\text { positive, equidistant weights which sum to one. IT Dependence RW is } \\
\text { this ranking. Source: Author's calculations using data from EU KLEMS. }\end{array}$ \\
\hline IT Price Ind & $\begin{array}{l}\text { The price of investments in information technologies relative to the price } \\
\text { of value added in sample industries. In contrast to IT Price, this variable } \\
\text { is not averaged across industries. Source: EU KLEMS. }\end{array}$ \\
\hline IT Investments & $\begin{array}{l}\text { The ratio of real investments in information technologies and real value } \\
\text { added in sample industries. Source: EU KLEMS. }\end{array}$ \\
\hline
\end{tabular}




\section{Online Technical Appendix}

In this section, I consider a two-sector extension of the model presented in the main text and endogenize the allocation of information technologies between sectors. I show that parameter $\alpha_{I T}$ is a primary and key source of variation in the main measure of dependence on information technologies, which is defined as the share of compensation of information technologies out of value added.

I assume that final output is given by

$$
Y=Y_{1}^{\sigma_{1}} Y_{2}^{\sigma_{2}}
$$

where $\sigma_{1}>0, \sigma_{2}>0, \sigma_{1}+\sigma_{2}=1$, and

$$
Y_{i}=\left(\alpha_{I T, i} I T_{i}^{\frac{\varepsilon-1}{\varepsilon}}+\alpha_{T_{R}} T_{R, i}^{\frac{\varepsilon-1}{\varepsilon}}\right)^{\frac{\varepsilon}{\varepsilon-1} \alpha} T_{A, i}^{1-\alpha}, i=1,2
$$

I also assume that $\alpha_{I T, 1}>\alpha_{I T, 2}$ so that industry 1 depends on information technologies

more than industry 2. Total supplies of factor inputs are given by $I T=\lambda \widehat{I T}, T_{R}$, and $T_{A}$.

It follows from equations (11) and (12) that the demand for the output of industry $i$ $(i=1,2)$ and the demand for factor inputs of that industry are given by

$$
p_{Y_{i}} Y_{i}=\sigma_{i} Y
$$

and

$$
\begin{aligned}
I T_{i} & =\alpha \frac{\alpha_{I T, i} I T_{i}^{\frac{\varepsilon-1}{\varepsilon}}}{\alpha_{I T, i} I T_{i}^{\frac{\varepsilon-1}{\varepsilon}}+\alpha_{T_{R}} T_{R, i}^{\frac{\varepsilon-1}{\varepsilon}}} \frac{p_{Y_{i}}}{p_{I T}} Y_{i}, \\
T_{R, i}= & \alpha \frac{\alpha_{T_{R}} T_{R, i}^{\frac{\varepsilon-1}{\varepsilon}}}{\alpha_{I T, i} I T_{i}^{\frac{\varepsilon-1}{\varepsilon}}+\alpha_{T_{R}} T_{R, i}^{\frac{\varepsilon-1}{\varepsilon}} \frac{p_{Y_{i}}}{p_{T_{R}}} Y_{i},} \\
T_{A, i}= & (1-\alpha) \frac{p_{Y_{i}}}{p_{T_{A}}} Y_{i},
\end{aligned}
$$

where I have normalized the price of final output to 1. 
Equilibrium allocations of information technologies and task inputs in industries can be solved from equations (12)-(16) and market clearing conditions

$$
\begin{aligned}
& I T_{1}+I T_{2}=\lambda \widehat{I T}, \\
& T_{R, 1}+T_{R, 2}=T_{R}, \\
& T_{A, 1}+T_{A, 2}=T_{A} .
\end{aligned}
$$

It is straightforward to show that these allocations are given by

$$
\begin{aligned}
& \frac{T_{R}-T_{R, 1}}{T_{R, 1}}=\left(\frac{\alpha_{I T, 1}}{\alpha_{I T, 2}}\right)^{\varepsilon} \frac{I T-I T_{1}}{I T_{1}}, \\
& \frac{\alpha_{T_{R}} T_{R, 1}^{\frac{\varepsilon-1}{\varepsilon}}}{\alpha_{I T, 1} I T_{1}^{\frac{\varepsilon-1}{\varepsilon}}+\alpha_{T_{R}} T_{R, 1}^{\frac{\varepsilon-1}{\varepsilon}}} \frac{1}{T_{R, 1}}=\frac{\sigma_{2}}{\sigma_{1}} \frac{1}{T_{R}-T_{R, 1}} \times \\
& \frac{\alpha_{T_{R}}\left(T_{R}-T_{R, 1}\right)^{\frac{\varepsilon-1}{\varepsilon}}}{\alpha_{I T, 2}\left(I T-I T_{1}\right)^{\frac{\varepsilon-1}{\varepsilon}}+\alpha_{T_{R}}\left(T_{R}-T_{R, 1}\right)^{\frac{\varepsilon-1}{\varepsilon}}}, \\
& \frac{\alpha_{T_{R}} T_{R, 1}^{\frac{\varepsilon-1}{\varepsilon}}}{\alpha_{I T, 1} I T_{1}^{\frac{\varepsilon-1}{\varepsilon}}+\alpha_{T_{R}} T_{R, 1}^{\frac{\varepsilon-1}{\varepsilon}}} \frac{T_{A, 1}}{T_{R, 1}}=\frac{T_{A}-T_{A, 1}}{T_{R}-T_{R, 1}} \times \\
& \frac{\alpha_{T_{R}}\left(T_{R}-T_{R, 1}\right)^{\frac{\varepsilon-1}{\varepsilon}}}{\alpha_{I T, 2}\left(I T-I T_{1}\right)^{\frac{\varepsilon-1}{\varepsilon}}+\alpha_{T_{R}}\left(T_{R}-T_{R, 1}\right)^{\frac{\varepsilon-1}{\varepsilon}}},
\end{aligned}
$$

where the first two equations solve for the allocations of information technologies and routine tasks, and the last equation solves for the shares of abstract tasks in industries (the allocations of abstract tasks).

In this model, the shares of compensation of information technologies out of value added in industry 1 and 2 are given by

$$
\begin{aligned}
& \frac{p_{I T} I T_{1}}{p_{Y_{1}} Y_{1}}=\alpha \frac{\alpha_{I T, 1}\left(\frac{I T_{1}}{T_{R, 1}}\right)^{\frac{\varepsilon-1}{\varepsilon}}}{\alpha_{I T, 1}\left(\frac{I T_{1}}{T_{R, 1}}\right)^{\frac{\varepsilon-1}{\varepsilon}}+\alpha_{T_{R}}}, \\
& \frac{p_{I T} I T_{2}}{p_{Y_{2}} Y_{2}}=\alpha \frac{\alpha_{I T, 1}\left(\frac{\alpha_{I T, 2}}{\alpha_{I T, 1}}\right)^{\varepsilon}\left(\frac{I T_{1}}{T_{R, 1}}\right)^{\frac{\varepsilon-1}{\varepsilon}}}{\alpha_{I T, 1}\left(\frac{\alpha_{I T, 2}}{\alpha_{I T, 1}}\right)^{\varepsilon}\left(\frac{I T_{1}}{T_{R, 1}}\right)^{\frac{\varepsilon-1}{\varepsilon}}+\alpha_{T_{R}}} .
\end{aligned}
$$


Clearly, these shares are equal when $\alpha_{I T, 1}=\alpha_{I T, 2}$ and

$$
\frac{p_{I T} I T_{1}}{p_{Y_{1}} Y_{1}}>\frac{p_{I T} I T_{2}}{p_{Y_{2}} Y_{2}}
$$

when $\alpha_{I T, 1}>\alpha_{I T, 2}$, which means that industries with a higher $\alpha_{I T}$ have a higher share of compensation of information technologies. I utilize exactly this relationship in the empirical analysis.

There can be confounding factors which create a variation in the shares of compensation of information technologies. According to this model, one such factor can be $\alpha_{T_{R}}$ if it is different across industries. I check the robustness of the empirical exercise to variation in $\alpha_{T_{R}}$ in Panel $\mathrm{F}$ of Table 5. Moreover, I check that the proxy for dependence on IT is highly correlated with other proxies commonly used in the literature. ${ }^{5}$

It can also be shown that the key results of the model presented in the main text hold in this general equilibrium setting. After some algebra, it can be shown that the share of abstract tasks in industry 1 increases relative to the share of abstract tasks in industry 2 as $\lambda$ grows. The share of routine tasks in industry 1 declines relative to the share of routine tasks in industry 2 with $\lambda$ :

$$
\begin{gathered}
\frac{\partial}{\partial \lambda} \frac{T_{A, 1}}{T_{R, 1}+T_{A, 1}} / \frac{T_{A, 2}}{T_{R, 2}+T_{A, 2}}>0, \\
\frac{\partial}{\partial \lambda} \frac{T_{R, 1}}{T_{R, 1}+T_{A, 1}} / \frac{T_{R, 2}}{T_{R, 2}+T_{A, 2}}<0 .
\end{gathered}
$$

The price of information technologies falls as $\lambda$ grows. ${ }^{6}$

\footnotetext{
${ }^{5}$ Industry specific subsidies for the use of IT also can create confounding variation. Such a variation can be expected to be weak given that the shares of IT compensation are highly correlated across countries. Moreover, it is likely to be minimized with the use of US data which is arguably the closest to the laissez faire.

${ }^{6}$ It is also possible to endogenize the supply of labor to tasks as in the main text and show that the share of employment in abstract tasks grows with $\lambda$ and it is lower in industries with a lower $\alpha_{I T}$, as well as in groups of labor which have a higher $\alpha_{L, T_{R}}$.
} 


\section{References}

Autor, D. H., Dorn, D. and Hanson, G. H. (2015). 'Untangling trade and technology: Evidence from local labour markets', Economic Journal, Vol. 125, pp. 621-646.

Cerina, F., Moro, A. and Rendall, M. (2017). The role of gender in employment polarization. CMF Discussion Paper No. 2017-04.

Chen, W., Niebel, T. and Saam, M. (2016). 'Are intangibles more productive in ICTintensive industries? Evidence from EU countries', Telecommunications Policy, Vol. 40, pp. $471-484$.

Goos, M., Manning, A. and Salomons, A. (2014). 'Explaining job polarization: Routinebiased technological change and offshoring', American Economic Review, Vol. 104, pp. $2509-2526$.

Jerbashian, V. and Kochanova, A. (2016). 'The impact of doing business regulations on investments in ICT', Empirical Economics, Vol. 50, pp. 991-1008.

Jerbashian, V. and Kochanova, A. (2017). 'The impact of telecommunication technologies on competition in services and goods markets: Empirical evidence', Scandinavian Journal of Economics, Vol. 119, pp. 628-655.

Michaels, G., Natraj, A. and van Reenen, J. (2014). 'Has ICT polarized skill demand? Evidence from eleven countries over twenty-five years', Review of Economics and Statistics, Vol. 96, pp. 60-77. 